\title{
Global Evaluation of Gridded Satellite Precipitation Products from the NOAA Climate Data Record Program
}

\author{
Olivier P. Prat, ${ }^{\mathrm{a}}$ Brian R. NELSON, ${ }^{\mathrm{b}}$ ElsA NiCKL, ${ }^{\mathrm{c}}$ AND RONALD D. LEEPER ${ }^{\mathrm{a}}$ \\ ${ }^{a}$ Cooperative Institute for Satellite Earth System Studies, North Carolina State University, Asheville, North Carolina \\ ${ }^{\mathrm{b}}$ Center for Weather and Climate, NOAA/NESDIS/NCEI, Asheville, North Carolina \\ ${ }^{\mathrm{c}}$ Department of Geography, University of Delaware, Newark, Delaware
}

(Manuscript received 17 October 2020, in final form 6 May 2021)

\begin{abstract}
Three satellite gridded daily precipitation datasets-PERSIANN-CDR, GPCP, and CMORPH-that are part of the NOAA/Climate Data Record (CDR) program are evaluated in this work. The three satellite precipitation products (SPPs) are analyzed over their entire period of record, ranging from over 20 years to over 35 years. The products intercomparisons are performed at various temporal (daily to annual) resolutions and for different spatial domains in order to provide a detailed assessment of each SPP strengths and weaknesses. This evaluation includes comparison with in situ datasets from the Global Historical Climatology Network (GHCN-Daily) and the U.S. Climate Reference Network (USCRN). While the three SPPs exhibited comparable annual average precipitation, significant differences were found with respect to the occurrence and the distribution of daily rainfall events, particularly in the low and high rainfall rate ranges. Using USCRN stations over CONUS, results indicated that CMORPH performed consistently better than GPCP and PERSIANNCDR for the usual metrics used for SPP evaluation (bias, correlation, accuracy, probability of detection, and false alarm ratio, among others). All SPPs were found to underestimate extreme rainfall (i.e., above the 90th percentile) from about $-20 \%$ for CMORPH to $-50 \%$ for PERSIANN-CDR. Those differences in performance indicate that the use of each SPP has to be considered with respect to the application envisioned, from the long-term qualitative analysis of hydroclimatological properties to the quantification of daily extreme events, for example. In that regard, the three satellite precipitation CDRs constitute a unique portfolio that can be used for various long-term climatological and hydrological applications.
\end{abstract}

KEYWORDS: Atmosphere; Climate records; Hydrometeorology; Precipitation; Rainfall; Remote sensing; Satellite observations

\section{Introduction}

Since the 1960s, weather and environmental satellites have provided valuable observations of the earth and the atmosphere. The number of atmospheric and environmental variables being monitored has constantly increased since. As the period of observation grows, global satellites products constitute an invaluable complement to in situ observations that are spatially limited by nature. They have become suitable to investigate weather variability and climate trends in support of economic vitality, energy, agriculture, water resources, human health, public safety, community resilience to climate change, and national security.

In this work, we focus on three gridded daily satellite precipitation products (SPPs) that are part of the NOAA/NCEI's Climate Date Record (CDR) portfolio. Briefly, satellite based Climate Data Records were created to address the need for essential climate variables (ECVs) as identified by the Global Climate Observing System (GCOS). A CDR is defined as a dataset of environmental variables that satisfy the criteria of length of record, consistency, and continuity (National Research Council 2004). NOAA's CDR program, which includes over 40 operational CDRs covering a wide range of environmental variables, is part of this effort to produce robust and scientifically sound climate records from satellite data (https:// www.ncdc.noaa.gov/cdr).

Corresponding author: Olivier P. Prat,opprat@ncsu.edu
The three precipitation CDRs, namely, PERSIANN-CDR, GPCP, and CMORPH were developed for long-term hydrological and climatic analysis and applications. Here, we use "long-term" in the context of satellite observation platforms that have time series spanning over two to three decades. Those SPPs are among the multitude of gridded SPPs that exist and that rely on different physical retrieval principles, different bias adjustment techniques and reference datasets (Michaelides et al. 2009; Kidd et al. 2010; Kidd and Huffman 2011; Tapiador et al. 2012; Prat and Nelson 2020). PERSIANNCDR, GPCP, and CMORPH have been used for numerous hydrological and climatological applications. Those SPPs have been the object of several evaluations against others SPPs, ground based radars, or in situ datasets (Tian et al. 2009; Hirpa et al. 2010; AghaKouchak et al. 2011, 2012; Gebremichael et al. 2014; Miao et al. 2015; Prat and Nelson 2015; KatiraieBoroujerdy et al. 2017; Beck et al. 2017, 2019a; Adler et al. 2018; Ferraro et al. 2018; Nguyen et al. 2018; Tan and Santo 2018; Sadeghi et al. 2019, among others). There are several challenges in evaluating SPPs and assessing their ability to accurately capture precipitation patterns and characteristics. All SPP evaluation studies face the obvious limitations that arise from comparing surface area precipitation estimates (pixel dimension of the SPP) with a point measurement (Ciach and Krajewski 1999; Ciach et al. 2003, 2007; Habib et al. 2004). Ideally, an evaluation of SPPs would require that the reference in situ dataset is not part of the SPP bias-adjustment procedure (Prat and Nelson 2014, 2015; Beck et al. 2017, 2019a). In recent studies, Beck et al. (2017, 2019a) have pointed out the three major 
challenges and limitations in evaluating SPPs. As mentioned, most available evaluations of SPPs 1) have used reference datasets that are also used in the calibration or the bias-adjustment procedure of the SPP, leading to biased evaluation; 2) were conducted locally using a limited number of gauges; and 3) have used daily accumulation as a function of the local time, which can cause a portion of the daily rainfall to be assigned to a different day than the SPP (see Beck et al. 2017, 2019a for review).

Most of the studies mentioned above have considered SPP evaluation over different regions. However, those evaluations were often limited in domain and/or in time. In fact, few studies have provided a global assessment and long-term performance evaluation of SPPs (e.g., Tian and Peters-Lidard 2010; Beck et al. 2017, 2019a; Massari et al. 2017; Nguyen et al. 2018; Sun et al. 2018). A long-term evaluation is particularly important in the context SPP applications to hydrological and hydroclimatological extremes such as extreme precipitation [see Tables 2 and 3 in Prat and Nelson (2020) for review] or drought detection and monitoring for instance (Prat et al. 2018, 2020). The aim of this work is to provide a comparative long-term evaluation of the three SPPs that are part of the CDR program. The evaluation is performed at temporal scales from annual to daily over their concurrent period of record from 1998 to 2018 (21 years). At the daily scale, the focus is to assess each SPP performance by quantifying errors and biases with respect to in situ data. Our goal is to address, at least partially, the points mentioned above by providing a long-term, global, and independent evaluation of each SPP. The latest point will be achieved by using gauges from the U.S. Climate Reference Network (USCRN) that are not used in SPP bias adjustment procedures. Ultimately, this work would provide an objective basis for merged precipitation product algorithm improvement.

The paper is organized as follows. The characteristics and underlying physical principles of the three SPPs (PERSIANNCDR, CMORPH, GPCP) to be evaluated are detailed in section 2. In situ datasets used as ground evaluation (GHCND, USCRN) are presented along with the digital elevation model (DEM) used to connect each satellite pixel to topographic features. Section 3 will present the results if the study and associated discussion. The section will be organized in two subsections. First, we present a global evaluation of the SPPs that will compare long-term average precipitation features for the three SPPs over their concurrent period of record. The comparison will be conducted at annual, seasonal, and daily scale. Each SPP will also be compared globally against GHCN$\mathrm{D}$ in situ data. In a second subsection, we will perform a more detailed analysis of the performances of the three SPPs over CONUS. An evaluation will be conducted by using rainfall observations from the USCRN stations. Finally, section 4 will summarize the most important findings of the study.

\section{Precipitation datasets and SPP algorithms description}

a. The satellite precipitation CDRs

\section{1) GPCP}

The Global Precipitation Climatology Project (GPCP) has a suite of products spanning various time and space scales
(Huffman et al. 2001). The GPCP-Monthly CDR is available for $90^{\circ} \mathrm{S}-90^{\circ} \mathrm{N}$ at a spatial resolution of $2.5^{\circ} \times 2.5^{\circ}$. The product is updated monthly as an Interim CDR (ICDR) with the final version (CDR) available after three months (Adler et al. 2017a). The global GPCP-Monthly product that is available starting in 1979, has been used extensively in long-term studies and hydroclimatic assessments. The daily product which is available since October 1996 has the same update frequency and geographical coverage $\left(90^{\circ} \mathrm{S}-90^{\circ} \mathrm{N}\right)$ than GPCP-Monthly but at a higher spatial resolution of $1^{\circ} \times 1^{\circ}$ (Adler et al. 2017b). The GPCP suite of products (monthly and daily) is a merged satellite (infrared and microwave) and in situ product (Fig. 1a). Both monthly and daily GPCP CDRs are available at the NOAA/National Centers for Environmental Information (NCEI) Climate Data Records portal. In this work, we use the daily version v01r03.

\section{2) PERSIANN-CDR}

The Precipitation Estimation from Remotely Sensed Information Using Artificial Neural Networks-Climate Data Record (PERSIANN-CDR) combines IR satellite precipitation estimates with a neural network technique along with a monthly bias correction using in situ data through GPCP monthly (Hsu et al. 2014; Ashouri et al. 2015). PERSIANN-CDR provides quasi-global $\left(60^{\circ} \mathrm{S}-60^{\circ} \mathrm{N}\right)$ daily precipitation estimate at a spatial resolution of $0.25^{\circ} \times 0.25^{\circ}$. PERSIANN-CDR is available from 1983 to the delayed present with a quarterly update frequency. The version used is v01r01. Figure $1 \mathrm{~b}$ summarizes the different sensors and ancillary products used in PERSIANN-CDR. For more detail of the algorithm, the reader can refer to Ashouri et al. (2015).

\section{3) $\mathrm{CMORPH}$}

The Climate Prediction Center (CPC) morphing technique (CMORPH) provides a precipitation estimates at the native temporal and spatial resolutions of $30 \mathrm{~min}$ and $8 \mathrm{~km} \times 8 \mathrm{~km}$, respectively, for the domain $60^{\circ} \mathrm{S}-60^{\circ} \mathrm{N}$ (Joyce et al. 2004). The product is also available at the hourly and daily scales at $0.25^{\circ} \times 0.25^{\circ}$. CMORPH combines precipitation estimates derived from passive microwave (PMW) sensors through the advection of cloud features from more frequently available infrared measurements (i.e., the morphing technique). The bias-adjusted version of the product uses daily surface gauge analysis from the CPC over land (Xie et al. 2010) and the Pentad version of GPCP over ocean (Xie et al. 2003) (Fig. 1c). More details regarding the CMORPH algorithm and precipitation products can be found in Xie et al. (2017, 2018). CMORPH is available from 1998 to the delayed present. A non-bias-adjusted CMORPH is available as an interim version within two days to the present date. The version used in this work is CMORPH V1.0. To avoid possible confusion with more recent versions of CMORPH under development, the version used in this work will be hereinafter referred as CMORPH-CDR.

The characteristics for each precipitation CDR are provided in Table 1. Figure 1 provides a schematic of the methods, physical principles, input datasets used, and dataset dependencies. It worth noticing that those SPPs can differ substantially 

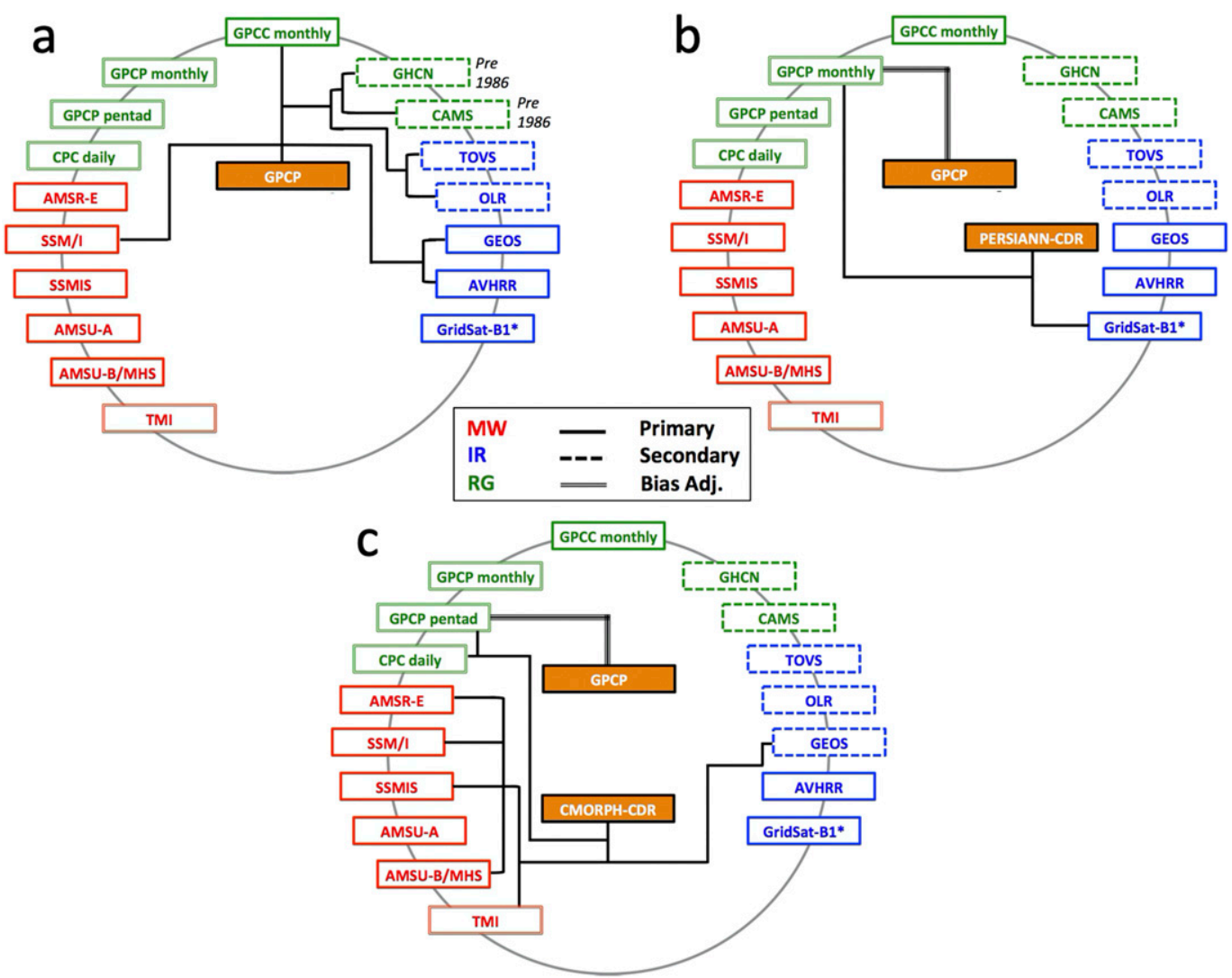

FIG. 1. Multisatellite products with the different sensors used (MW: microwave; IR: infrared; RG: rain gauge) in the three precipitation CDRs: (a) GPCP, (b) PERSIANN-CDR, and (c) CMORPH-CDR. The definition of each product acronyms is provided in the list at the end of the manuscript.

from their respective namesake with whom the precipitation and remotely sensed scientific community might be more familiar with. For instance, PERSIANN-CDR (Ashouri et al. 2015) is in nature a very different product than the original product it shares its name with (Sorooshian et al. 2000). PERSIANN-CDR relies on the fundamental CDR GRIDSAT B1 (i.e., Geostationary IR channel brightness temperature) as main input which provides quasi global $\left(70^{\circ} \mathrm{S}-70^{\circ} \mathrm{N}\right)$ IR brightness temperature every $3 \mathrm{~h}$ at an $8-\mathrm{km}$ resolution. Similarly, CMORPH-CDR is the bias corrected version (sometimes noted CRT) of the nearreal-time CMORPH and is available with a delay of four months once global gauge analysis (CPC) and GPCP-Pentad estimates are finalized. For the most recent period, the nearreal-time CMORPH is available within a day as an ICDR. Figure 1 shows the different input datasets and underlying physical principles that characterize the different satellite precipitation CDRs. PERSIANN-CDR is solely an IR product that uses in situ bias-adjustment procedure and another CDR (GPCP-Monthly) for calibration. GPCP is almost entirely an IR product with additional input from the Special Sensor Microwave Imager (SSM/I) based on PMW principles. Adjustment of the satellite derived global precipitation fields is performed at the monthly scale with in situ data from the Global Historical Climatological Network (GHCN) and from the Climate Anomaly Monitoring System (CAMS) for the years prior to 1986, and with gridded data from the Global Precipitation Climatology Centre (GPCC) for the most recent period. Because the bias-corrected PERSIANN-CDR uses GPCP-Monthly v02r02 to maintain consistency in monthly precipitation totals, the quality of precipitation estimates might depend to some extend on the biases present in GPCP. With GPCP being a merged product, biases are due to the degradation of individual satellite performance, algorithm differences, instrumental calibrations, sensor availability, transition between satellites with limited lifespan, and the evolution of gauges analysis among others (Adler et al. 2018). It is important to note that PERSIANN-CDR used GPCP-Monthly v02r02 that exhibit a slight and incorrect decrease in ocean precipitation for the years after 2002. Those biases were related to small shifts in the input of satellite precipitation estimates due to the transition from one satellite to the next and to the inadequate overlap and cross-validation procedures. The GPCP daily product (v01r03) evaluated in this study includes corrections to cross calibration of satellite data inputs and updates to the GPCC gauge analysis (Adler et al. 2018).

Conversely, CMORPH-CDR is mostly a PMW product but uses IR imagery from Geostationary Operational Environmental Satellites (GEOS) for the morphing technique and the cloud advection scheme. For the bias-adjustment procedure, CMORPH-CDR uses rain gauge data from the CPC 
TABLE 1. Satellite precipitation Climate Data Records (CDRs) and their characteristics. In bold are the SPPs used in this study.

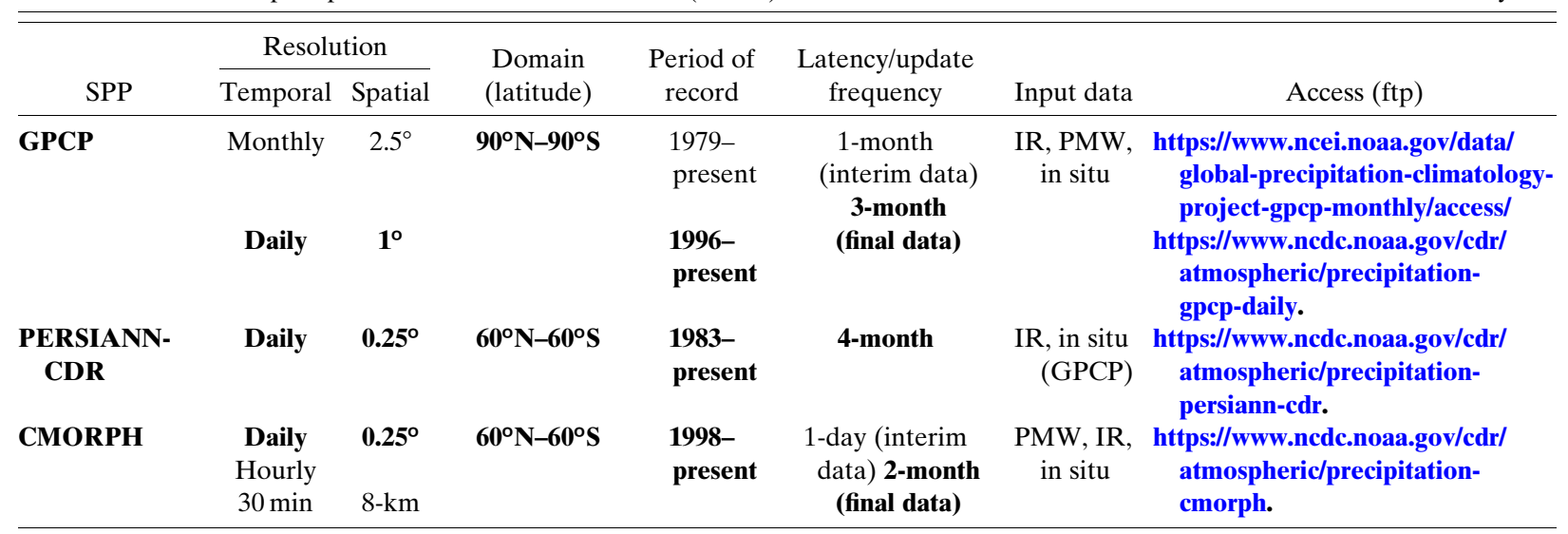

daily analysis over land and GPCP pentad over ocean (Xie et al. 2017, 2018). While the conversion from IR measurements is typically less accurate because they assume a simple dependency between the satellite measured cloud-top IR temperature and the rain rate, passive microwave methods by scanning through the precipitating systems are directly affected by the characteristic of the hydrometeors present within the atmospheric column, and thus considered more reliable (Prat and Nelson 2020).

\section{b. In situ quantitative precipitation estimates datasets}

\section{1) Global Historical Climatological NETWORK-DAILY}

Precipitation surface observations are taken from the Global Historical Climatology Network-Daily (GHCN-D). The dataset gathers records from over 100000 stations over 180 countries. About two-thirds of those stations report total daily precipitation only while the other stations include information such as maximum and minimum temperature, snowfall, and snow depth (Menne et al. 2012). The entire dataset is routinely quality controlled to ensure basic consistency. The daily accumulation for GHCN-D stations is a function of the local time while most daily satellite products report in UTC time (00000000 UTC). If the influence might be limited for evaluation over a multiday time scale (i.e., pentad, weekly, or monthly for instance), the impact at the daily scale could be nonnegligible.

\section{2) U.S. Climate Reference Network}

The U.S. Climate Reference Network (USCRN) is composed of about 140 stations in the United States and provides an ensemble of quality-controlled atmospheric parameters (rain rate, relative humidity, air temperature, and soil moisture for instance) at 5-min, 1-h, and 1-day temporal resolutions (Diamond et al. 2013; Leeper et al. 2015). From the 1-h rainfall accumulation, we can aggregate daily precipitation totals to the same daily accumulation than the SPPs (0000-0000 UTC). Data from the USCRN are used to evaluate daily precipitation estimates from the SPP CDR datasets over CONUS. The analysis covers the years 2007-18. The regional network identical to USCRN deployed in Alabama (ALCRN: 17 stations) is also included in the comparison. Additionally, USCRN stations were augmented by a higher-density network of U.S. Regional Climate Reference Network stations in the four corner states (Utah, Colorado, New Mexico, and Arizona) for a short period (2009-14), allowing for an analysis of 75 stations in this region over that period (hereinafter 4CCRN).

\section{c. Ancillary data: Digital elevation model}

To identify each pixel as an ocean or land grid point, along with its respective elevation, we use a DEM proposed by Nickl (2012). Topographic patterns can have significant influence on the spatial variability of land surface precipitation at global, regional, and local scales (Smith 1979; Barry 1992). The topographic variables considered are elevation $(z)$, longitudinal and latitudinal components of slope $(d z / d x, d z / d y)$ and exposure to orography $(E)$. Elevation is one of the most important topographic factors related to precipitation. On a mountain slope, forced uplift of air masses can cause precipitation to increase with elevation (orographic effect), depending on the size and orientation of the mountain (Smith 1979; Barry 1992; Daly et al. 1994). Slope and slope orientation have important effects on precipitation due to their effects on solar irradiation and exposure to winds carrying humidity (Barry 1992). Exposure to orography $E$ is represented by a heightened "exposure." An orographic area, for example, may exhibit a general windward orientation but it also may contain a hill with a higher elevation that may enhance the local orographic effect. To estimate exposure, the elevation of each grid cell is compared to the average elevation trend over the orographic area (Nickl 2012).

The relationship between topographic patterns $(z, d x / d z$, $d y / d z, E)$ and precipitation improves when the topographic patterns are averaged up to an appropriate spatial scale. This "optimum" spatial scale is known as the "orographic" scale or resolution, and it may vary spatially as well as temporally. Some authors have found that elevation, when averaged up to spatial scales of $2-15 \mathrm{~km}$ ( $\sim 1-8$-min resolution), is more correlated with station precipitation than the station's actual elevation (Spreen 1947; Burns 1953; Schermerhorn 1967; Hibbert 1977). Elevation at 0.5 -min resolution was obtained from global digital elevation model GTOPO30 (USGS 1996). Each satellite pixel and surface station are associated with the nearest grid 

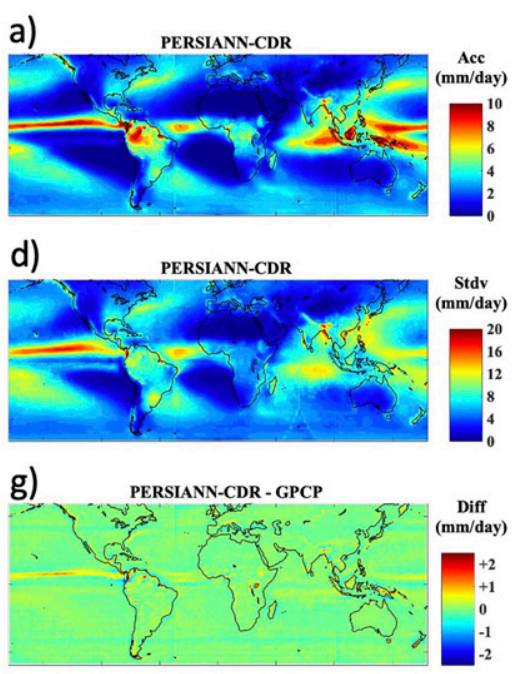

b)

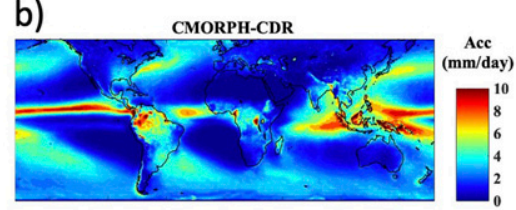

e)
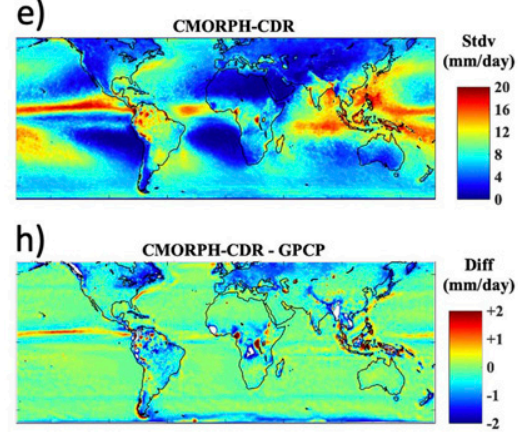

c)

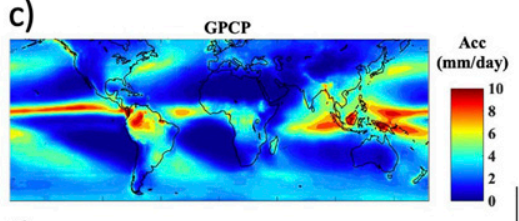

f)

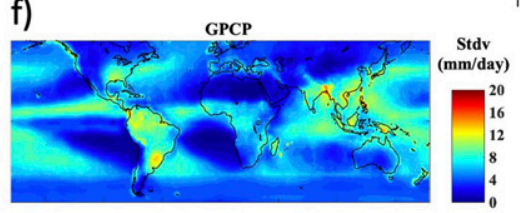

i)

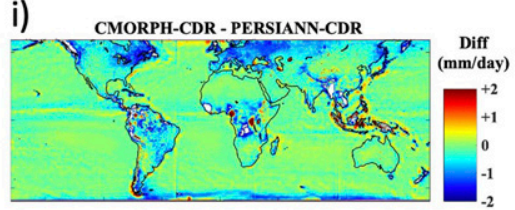

FIG. 2. (a)-(c) Average precipitation and (d)-(f) standard deviation for (left) PERSIANN-CDR, (center) CMORPH-CDR, and (right) GPCP. Differences in average rainfall between (g) PERSIANN-CDR and GPCP, (h) CMORPH-CDR and GPCP, and (i) CMORPHCDR and PERSIANN-CDR (i). Data are for the period 1998-2018.

point of GTOPO30, and then topographic information $(z, d z / d x$, $d z / d y, E)$ is averaged up from a higher resolution of $0.5 \mathrm{~min}$, to a coarser spatial resolution of $2.5 \mathrm{~min}$ to better describe overall relationships between satellite precipitation and topographic patterns. The longitudinal component of slope $(d z / d x)$ is estimated at each satellite pixel as the average of the differences in elevations between the east adjacent cell and the reference cell and between the west adjacent cell and the reference cell (south and north cells for the latitudinal component of slope: $d z / d y$ ). The grid area changes with latitude being accounted for; the same process is applied for the polar regions. A circle is used to bound and estimate the orographic area associated with a location of interest (in situ stations in general and satellite pixel in this case), and the average of the gridcell values within the circle is estimated for each topographic variable. Each satellite pixel at their native resolution $\left(1^{\circ} \times 1^{\circ}\right.$ for $\mathrm{GPCP}, 0.25^{\circ} \times 0.25^{\circ}$ for CMORPH-CDR and PERSIANN-CDR) is associated with elevation $(z)$, longitudinal and latitudinal components of slope $(d z / d x, d z / d y)$ and exposure to orography $(E)$ from the DEM.

\section{Results and discussion}

\section{a. Global evaluation of SPPS}

\section{1) LONG-TERM AVERAGE PRECIPITATION FEATURES}

Figure 2 displays the annual average daily precipitation from 1998 to 2018 for PERSIANN-CDR (Fig. 2a), CMORPH-CDR (Fig. 2b), and GPCP (Fig. 2c). Global precipitation patterns are comparable with zones of intense convection clearly recognizable such as along the intertropical convergence zone (ITCZ), the Kuroshio (coast of Japan), and the Gulf Stream (Atlantic Ocean). Over land, areas with the highest daily average rainfall are found over the Amazon, in Southwest India (Malabar Coast), the Philippines, the Himalayan Mountain range, and the Pacific Northwest (North America). The influence of the spatial resolution is clearly visible when looking at the standard deviation for annual precipitation (Figs. 2d-f). CMORPH-CDR $\left(0.25^{\circ} \times 0.25^{\circ}\right)$ displays the finer spatial features when comparing to GPCP $\left(1^{\circ} \times 1^{\circ}\right)$. PERSIANN-CDR also at $0.25^{\circ} \times 0.25^{\circ}$, displays a smoother pattern than CMORPH-CDR for the standard deviation because it is adjusted with GPCP-Monthly $\left(2.5^{\circ} \times 2.5^{\circ}\right)$. The "downscalingupscaling" process tends to "wash out" the precipitation features over the areas with higher average rainfall when regridded at the native resolution $\left(0.25^{\circ} \times 0.25^{\circ}\right)$. The highest daily rainfall variability is found over the areas of intense convective activity (ITCZ and land areas mentioned above) and over areas directly affected by climate indices such as ENSO (Pacific Ocean) for instance. A closer look at the differences in average rainfall between the SPPs (Figs. 2g-i), shows that PERSIANN-CDR and GPCP (Fig. 2g) remain relatively close, with the biggest differences located along the ITCZ. The similitudes between PERSIANN-CDR and GPCP are expected since PERSIANN-CDR used GPCP-Monthly for bias adjustment. As a result, the differences between CMORPH-CDR and GPCP (Fig. 2h) and CMORPH-CDR and PERSIANN-CDR (Fig. 2i), display similar patterns. The most important differences are found along the equator and at higher latitudes (eastern United States, Canada, Europe, Russia) where CMORPH-CDR displays significantly lower average rainfall than GPCP (Fig. 2h) and PERSIANN-CDR (Fig. 2i). CMORPH-CDR displays higher average rainfall over maritime Southeast Asia (Malaysia, Philippines, New Guinea) than the two other SPPs. Those differences will be analyzed more into details in an upcoming section.

Figure 3 displays the zonal averaged precipitation estimates over the temperate and tropical band $\left(50^{\circ} \mathrm{S}-50^{\circ} \mathrm{N}\right.$ : Figs. $\left.3 \mathrm{a}, \mathrm{c}\right)$ and over the tropical band $\left(23^{\circ} \mathrm{S}-23^{\circ} \mathrm{N}\right.$ : Figs. 3b,d). All SPPs display comparable latitudinal average precipitation on an 

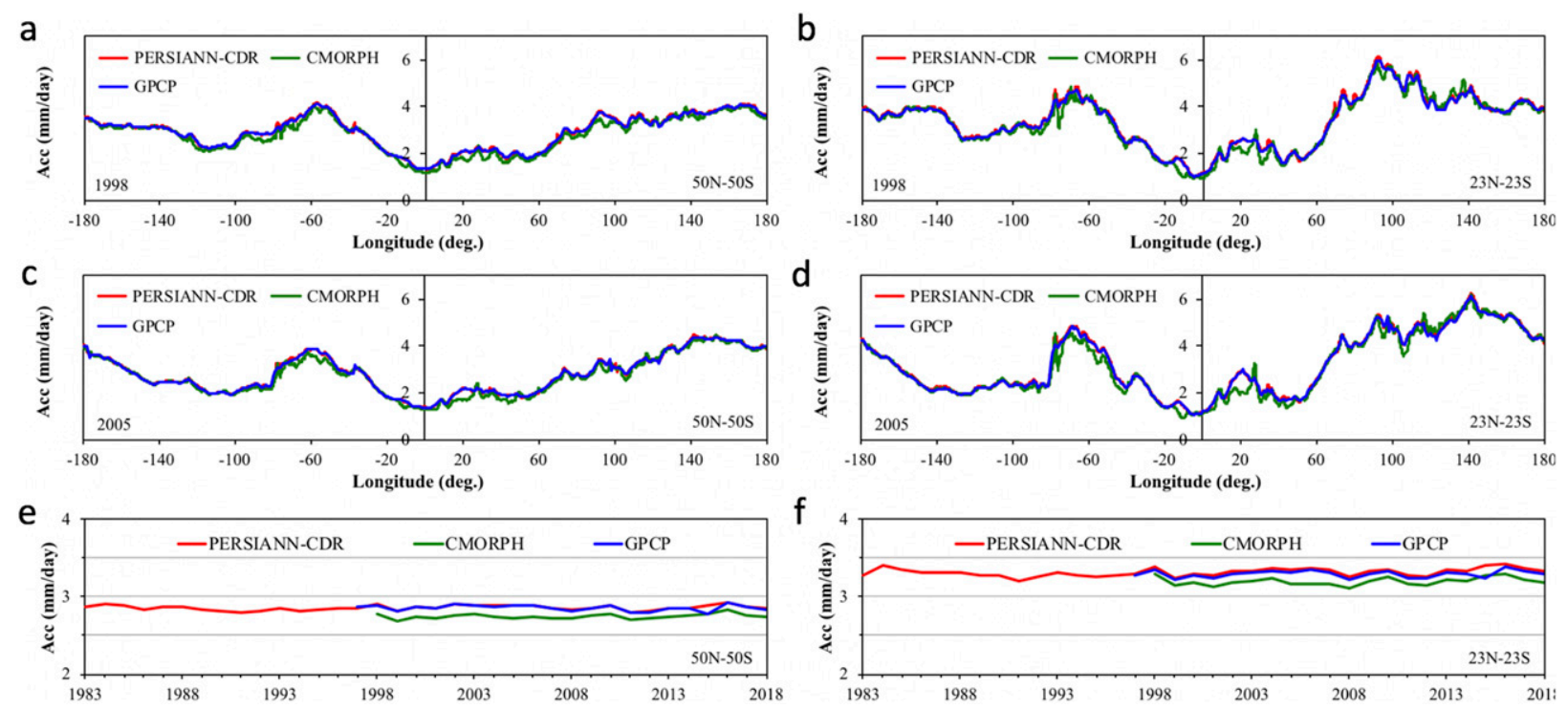

FIG. 3. (a)-(d) Satellite QPE products comparison of the zonal averaged precipitation estimates for (left) the globe $\left(50^{\circ} \mathrm{S}-50^{\circ} \mathrm{N}\right)$ and (right) the tropical band $\left(23^{\circ} \mathrm{S}-23^{\circ} \mathrm{N}\right)$ for the years 1998 in (a) and (b) and 2005 in (c) and (d) as a function of the longitude $\left(180^{\circ}-180^{\circ}\right)$. (e),(f) Evolution of the zonal averaged rainfall for (e) the globe and (f) the tropics presented for the period of record and for each product (lower row).

annual basis as illustrated by the years 1998 (Figs. 3a-b) and 2005 (Figs. 3c-d). There are noticeable differences over the tropical belt with CMORPH-CDR displaying more variability than PERSIANN-CDR and GPCP (Fig. 3b,d) which is consistent with the differences in standard deviation observed previously (Fig. 2). Differences can be attributed for the most part to the different rainfall retrieval methods used and to the different spatial resolution of the SPPs as mentioned earlier. Figures $3 \mathrm{e}-\mathrm{f}$ present a comparison of the annual daily average rainfall over the temperate and tropical domains (Fig. 3e) and over the tropics (Fig. 3f) over the respective period of record of each SPP. Over the concurrent period of record (1997-2018), PERSIANN-CDR and GPCP are quasi identical due to the fact that PERSIANN-CDR is bias-adjusted with GPCP-Monthly. With respect to the two other products, CMORPH-CDR presents slightly lower precipitation averages both for the temperate domain $\left(50^{\circ} \mathrm{S}-50^{\circ} \mathrm{N}\right)$ and over the tropics $\left(23^{\circ} \mathrm{S}-23^{\circ} \mathrm{N}\right)$. This average difference between CMORPH-CDR and the two other products is between $-4.0 \% \pm 0.15 \%\left(50^{\circ} \mathrm{S}-50^{\circ} \mathrm{N}\right)$ and $-3.4 \% \pm 0.5 \%\left(23^{\circ} \mathrm{S}-23^{\circ} \mathrm{N}\right)$ over the concurrent period of record (1998-2018).

\section{2) ANNUAL AND SEASONAL PRECIPITATION}

Figure 4 presents a comparison of the annual average precipitation for the SPPs over ocean (Fig. 4a), over land (Fig. 4b), and for elevation above $1000 \mathrm{~m}$ as defined by the DEM (Fig. 4c). The values for the average rainfall and the differences between the SPPs are reported in Table 2. Over ocean (Fig. 4a), all CDRs display the same annual average daily rainfall with less than $1 \%$ difference between the three SPPs over the period 1998-2018. This similarity is not surprising since both PERSIANN-CDR and CMORPH-CDR use GPCP as an input for bias adjustment (GPCP-Monthly or GPCP-Pentad, respectively). Over land (Fig. 4b), PERSIANN-CDR and GPCP remain similar for the same reasons with differences of about $1.2 \%$. Conversely, CMORPH-CDR displays lower average daily rainfall than the two other SPPs with differences of about $-14 \%$. Over land, CMORPH-CDR uses in situ information from the CPC daily analysis for bias-adjustment (Xie et al. 2010). As shown previously (Fig. 2), CMORPH-CDR presents important differences with GPCP (Fig. 2h) and PERSIANN-CDR (Fig. 2i) with lower average rainfall over the eastern United States and Canada and over Europe and Russia. Those differences are not compensated by higher rainfall observed over maritime Southeast Asia. For elevation above $1000 \mathrm{~m}$, average rainfall is lower than over land for the three SPPs (Fig. 4c). Like previously, PERSIANN-CDR and GPCP are relatively close with differences of about $3 \%$, while CMORPH-CDR presents a lower average daily rainfall when compared to the two other SPPs of about $-18 \%$.

A monthly analysis is provided in Fig. 5 comparing the daily average precipitation over land for January (Figs. 5a-c) and July (Figs. 5d-f). Furthermore, the analysis was conducted successively over the northern and southern hemispheres to investigate differences between the cold and warm seasons. Regardless of the month and the geographical area considered, PERSIANN-CDR and GPCP display comparable average rainfall. Average rainfall is higher in July (Fig. 5d) than in January (Fig. 5a). More specifically, we find higher average rainfall during the warm season; July in the Northern Hemisphere (Fig. 5e) and January in the Southern Hemisphere (Fig. 5c) than during the cold season; January in the Northern Hemisphere (Fig. 5b) and July on the Southern Hemisphere (Fig. 5f). The average differences between PERSIANN-CDR and GPCP remain below $1 \%$ for all the cases presented (Table 2). CMORPH-CDR displays lower rainfall averages than the two 

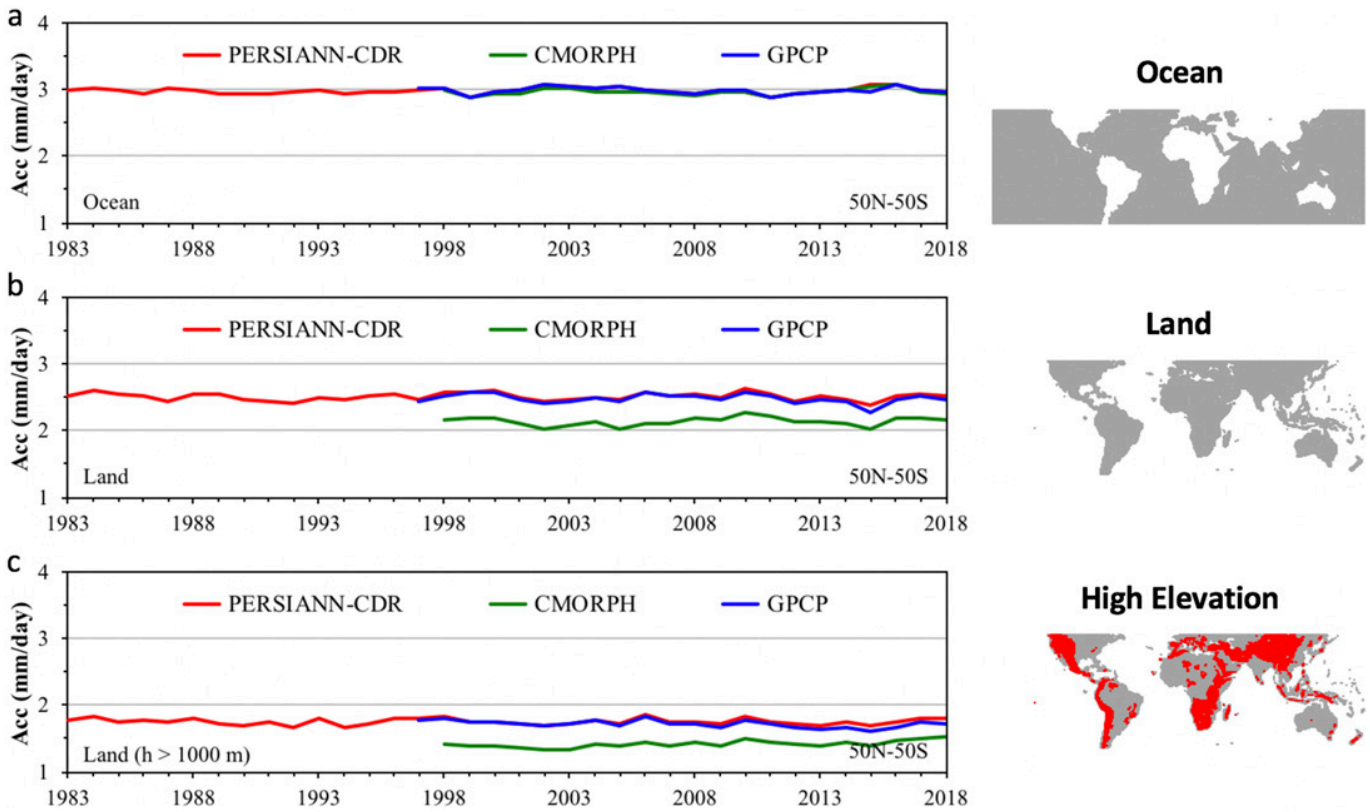

FIG. 4. Average annual precipitation for selected areas (ocean, land, high elevation) for PERSIANN-CDR, CMORPH-CDR, and GPCP. Ocean and land information along with elevation information are derived from the DEM at the same spatial resolution than the respective SPP CDR product, which is $0.25^{\circ}$ for PERSIANN-CDR and CMORPH-CDR and $1^{\circ}$ for GPCP.

other SPPs (Figs. 5a-f). Those differences range between $-8 \%$ for July in the Southern Hemisphere (Fig. 5f) and $-38 \%$ for January in the Northern Hemisphere (Fig. 5b). The differences between CMORPH and the two other SPPs are more important in the Northern Hemisphere with $-38 \%$ in January (Fig. 5b) and $-15 \%$ in July (Fig. 5e) which corresponds to the cold and warm season, respectively (Table 2). In the Southern Hemisphere, those differences are relatively close with $-11 \%$ in January (Fig. 5c) and $-8 \%$ in July (Fig. 5f), which correspond to the warm and cold seasons, respectively. The differences being more important in the Northern Hemisphere is consistent with results presented in Fig. 2, which showed lower average rainfall for CMORPH-CDR at higher latitudes over North America, Europe, and Asia (Fig. 2h). Finally, the fact that the differences between CMORPH-CDR and the two other SPPs are the most important during the cold season in the Northern Hemisphere (Fig. 5b), is possibly due to the inability for microwave sensors to retrieve precipitation over snow covered surface (Tian et al. 2009; Beck et al. 2019a).

\section{3) DAILY PRECIPITATION CHARACTERISTICS}

Figure 6 displays the value of the maximum daily precipitation (Figs. 6a-c) along with the average number of rainy days (Figs. 6d-f). The three SPPs exhibit large differences when it comes to the value of the maximum daily precipitation (Figs. 6a-c). CMORPH-CDR displays significantly higher maximum rainfall (Fig. 6b) than PERSIANN-CDR (Fig. 6a) and GPCP that displays much lower maximum daily rainfall

TABLE 2. Average annual daily precipitation (ocean, land, high elevation) and average monthly daily precipitation for the months of January (JAN) and July (JUL) over land (global and Northern and Southern Hemispheres) for GPCP, PERSIANN-CDR (PERS), and CMORPH-CDR (CMOR). The differences between the three SPPs are also reported.

\begin{tabular}{|c|c|c|c|c|c|c|}
\hline & \multicolumn{3}{|c|}{ Average daily rainfall $\left(\mathrm{mm} \mathrm{day}^{-1}\right)$} & \multicolumn{3}{|c|}{ Differences (\%) } \\
\hline & GPCP & PERS & CMOR & PERS - GPCP & CMOR - GPCP & CMOR - PERS \\
\hline Ocean & $2.99 \pm 0.10$ & $2.97 \pm 0.10$ & $2.97 \pm 0.10$ & -0.7 & -0.7 & 0.0 \\
\hline Land & $2.49 \pm 0.16$ & $2.52 \pm 0.12$ & $2.14 \pm 0.13$ & 1.2 & -14.1 & -15.1 \\
\hline High elevation $(h>1000 \mathrm{~m})$ & $1.71 \pm 0.12$ & $1.76 \pm 0.08$ & $1.42 \pm 0.11$ & 2.9 & -17.0 & -19.3 \\
\hline Land (JAN) & $2.49 \pm 0.22$ & $2.51 \pm 0.20$ & $2.00 \pm 0.20$ & 0.8 & -19.7 & -20.3 \\
\hline Northern Hemisphere (JAN) & $1.16 \pm 0.23$ & $1.17 \pm 0.19$ & $0.72 \pm 0.18$ & 0.9 & -37.9 & -38.5 \\
\hline Southern Hemisphere (JAN) & $5.34 \pm 0.52$ & $5.39 \pm 0.64$ & $4.77 \pm 0.73$ & 0.9 & -10.7 & -11.5 \\
\hline Land (JUL) & $2.71 \pm 0.31$ & $2.71 \pm 0.34$ & $2.34 \pm 0.25$ & 0.0 & -13.7 & -13.7 \\
\hline Northern Hemisphere (JUL) & $3.32 \pm 0.41$ & $3.33 \pm 0.45$ & $2.84 \pm 0.31$ & 0.3 & -14.5 & -14.7 \\
\hline Southern Hemisphere (JUL) & $1.39 \pm 0.25$ & $1.38 \pm 0.27$ & $1.27 \pm 0.29$ & -0.7 & -8.6 & -8.0 \\
\hline
\end{tabular}



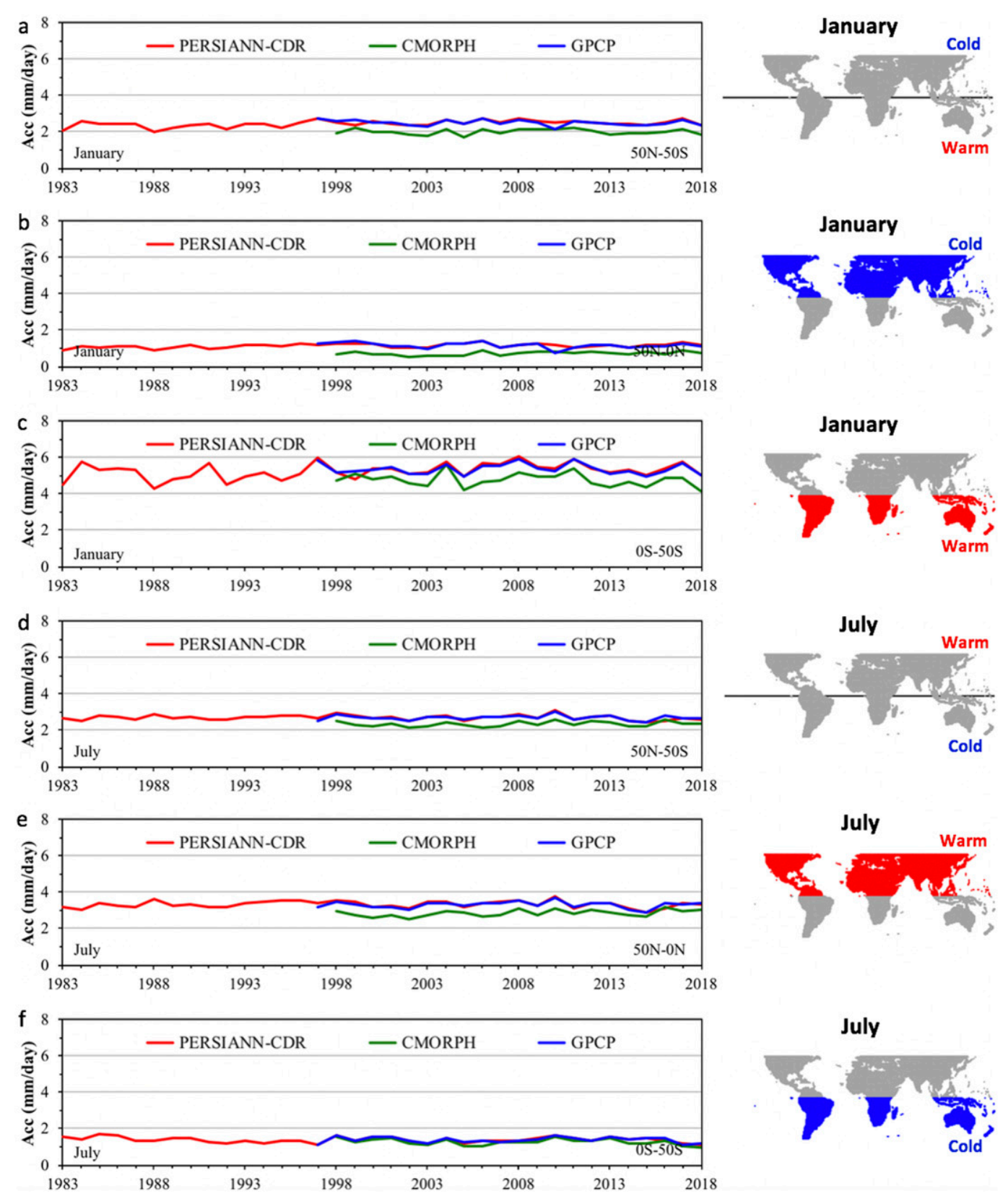

FIG. 5. Average precipitation overland for the months of (a)-(c) January and (d)-(f) July for PERSIANN-CDR, CMORPH-CDR, and GPCP. Results are provided for the entire globe in (a) and (d), the Northern Hemisphere in (b) and (e), and the Southern Hemisphere in (c) and (f) for January and July, respectively.

(Fig. 6c). At higher latitudes (i.e., above $40^{\circ} \mathrm{N}$ and below $40^{\circ} \mathrm{S}$ ), we note very low values for the maximum daily precipitation for GPCP and to a lesser extend for PERSIANN-CDR. As reported elsewhere, differences between the three SPPs increased with increasing daily rain rates (Prat and Nelson 2020). Those differences ranged from $40 \%, 67 \%$, and $100 \%$ at the 70th, 90th, and 99th percentiles, respectively.

Large differences are also found in the number of rainy days (Figs. 6d-i). Over the ocean, PERSIANN-CDR (Fig. 6b) displays significantly less rainy days than CMORPH-CDR (Fig. 6i) and
GPCP (Fig. 6g). This is particularly noticeable along the ITCZ. At higher latitudes, GPCP exhibits a higher number of rainy days than PERSIANN-CDR (Fig. 6g) and CMORPH-CDR (Fig. 6h). Over land, the higher number of precipitation days are found along the tropics for the three SPPs (Figs. 6d-f). Along the equatorial belt, PERSIANN-CDR (Fig. 6d) displays the highest number of rainfall days, followed by GPCP (Fig. 6f) and CMORPH-CDR displaying a significantly lower number of rainy days further restricted to a smaller land area (Fig. 6e). Outside of the equatorial belt $\left(23^{\circ} \mathrm{S}-23^{\circ} \mathrm{N}\right), \mathrm{CMORPH}-\mathrm{CDR}$ 
a)

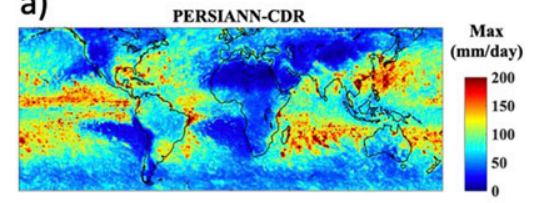

d)

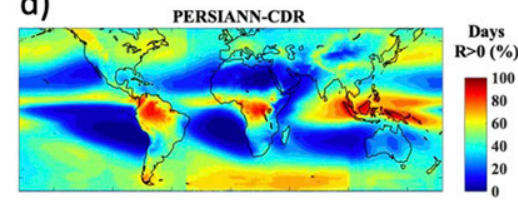

g)

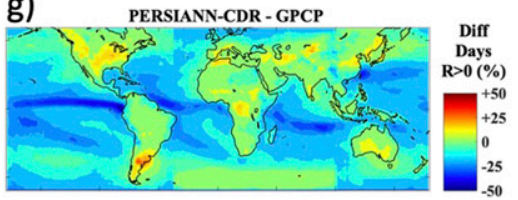

b)

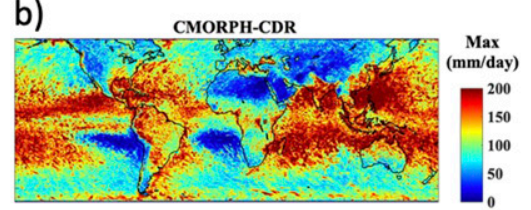

e)

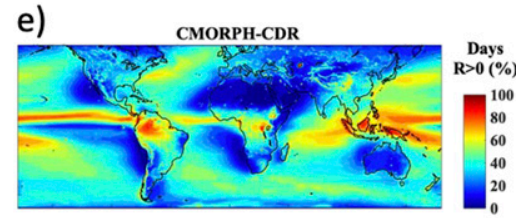

h)

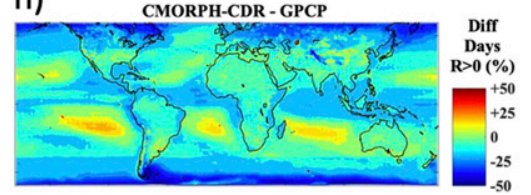

c)

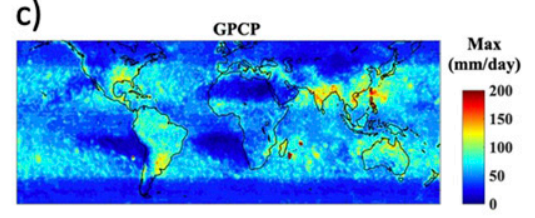

f)

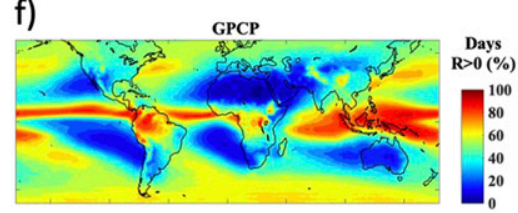

i)

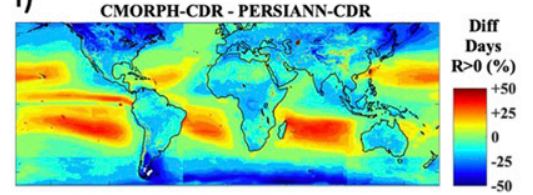

FIG. 6. (a)-(c) Daily maximum rainfall, (d)-(f) number of rainy days for (left) PERSIANN-CDR, (center) CMORPH-CDR, and (right) GPCP for the period 1998-2018. Differences in the number of rainy days between (g) PERSIANN-CDR and GPCP, (h) CMORPH-CDR and GPCP, and (i) PERSIANN-CDR and CMORPH-CDR.

displays the lowest number of rainfall days (Fig. 6e) when compared to PERSIANN-CDR (Fig. 6i) and GPCP (Fig. 6g). For CMORPH-CDR the spatial distribution of rainy days aligns more distinctively with orographic land characteristics when compared to the other SPPs as can be seen over the mountainous areas of the Rockies in the western United States, the Himalayas, and the Andes (Fig. 6e). Over CONUS, PERSIANN-CDR presents a higher number of rainy days than GPCP (Fig. 6g) and CMORPH-CDR (Fig. 6i). Globally, PERSIANN-CDR displays more rainy days in most land areas in Africa, Australia, and North and South America than GPCP and CMORPH-CDR, except over northern Europe where GPCP has more rainy days. Results obtained for CMORPHCDR, for the spatial repartition of maximum rainfall (Fig. 6b) and percent of rainy days (Fig. 6e) are comparable with other studies (Beck et al. 2019b). Over land, apart from some localized areas such as the Himalayas, CMORPH-CDR has a lower number of rainy days when compared to PERSIANNCDR and GPP and a lower average daily rainfall as shown previously (Figs. 4 and 5). At higher latitudes in the northern (North America, Europe, Asia) and southern (Argentina) hemispheres, CMORPH-CDR indicates a lower number of rainy days (Figs. 6h-i), which corresponds to a lower average daily rainfall (Figs. $2 \mathrm{~h}-\mathrm{i}$ ). Rainfall retrievals are knowingly a challenge for microwave sensors over land covered snow during the cold season (Tian et al. 2009; Stampoulis and Anagostou 2012; Beck et al. 2019a). It is interesting to notice that over the ocean gyres (North and South Pacific, North and South Atlantic, Indian Ocean), CMORPH-CDR indicates more rainy days than GPCP (Fig. 6h) and PERSIANN-CDR (Fig. 6i). However, this does not translate by an increase in average daily precipitation when compared to GPCP (Fig. 2g) and PERSIANN-CDR (Fig. 2i) because GPCP is being used as bias adjustment over ocean. Similarly, PERSIANN-CDR displays similar average daily precipitation when compared to
GPCP (Fig. 2g) despite having a higher number of rainy days (Fig. 6g), because GPCP is used for bias adjustment over land and over ocean (Figs. 4 and 5).

The differences, in terms of maximum daily precipitation and daily precipitation occurrence, can be explained by the limitations inherent to each remotely sensed technique (infrared, microwave), sensor sensitivity in detecting light rainfall events, and the bias-adjustment procedures used can be cited as the most likely causes. The similarities regarding average daily rainfall are explained by the bias-adjustment procedure and the product (in situ, satellite) used as reference.

\section{4) COMPARISON WITH GHCN-D IN SITU DATA}

A contingency analysis for daily rainfall $\left(R>0 \mathrm{~mm} \mathrm{day}^{-1}\right)$ is provided at each GHCN-D station reporting at least $90 \%$ of the time for the year 2013 (Fig. 7). Each SPP-PERSIANNCDR, CMORPH-CDR, and GPCP-display the same global pattern for misses (Figs. 7a-c), hits (Figs. 7d-f), and false alarm (Figs. $7 \mathrm{~g}-\mathrm{i}$ ). We note that all SPPs display the highest number of hits (i.e., rain detected simultaneously by the gauge location and at the corresponding satellite pixel) over the eastern United States. Conversely, there is a higher number of false alarm (i.e., rain detected by the satellite only) over the western United States. Those differences could be due to the type of precipitation over the Rockies and the convective and localized nature of precipitation over mountainous areas. The difference between the gauges local reporting time that varies over CONUS (Menne et al. 2012) and the satellite daily accumulation could also explain the differences between the west and the east. If the mismatch between GHCN-D and satellite products is important (from a few hours to half a day), this could result in a significant portion of daily rainfall to be assigned to the wrong neighboring day (Beck et al. 2019b). Australia presents a lower number of hits and a higher number of false alarm comparable to those found over the western 
a)

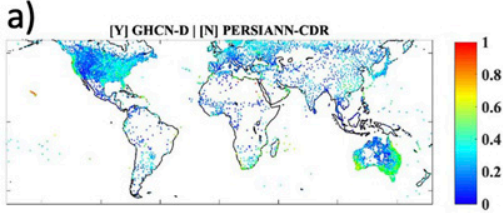

d)

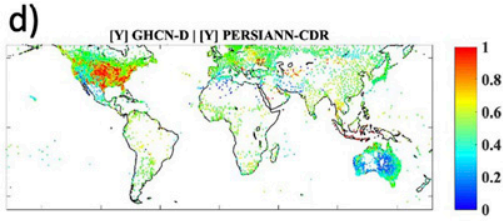

g)

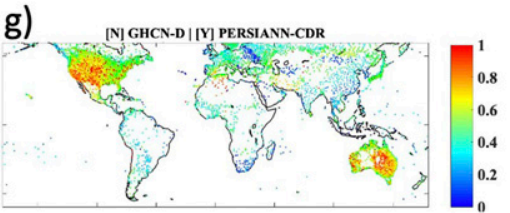

b)

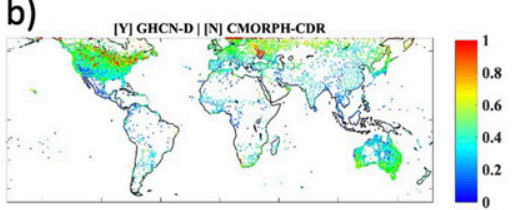

e)

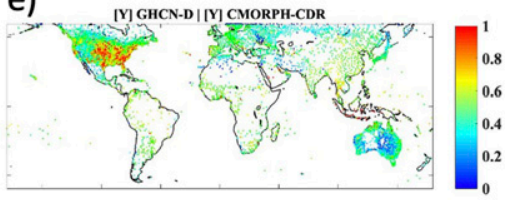

h)

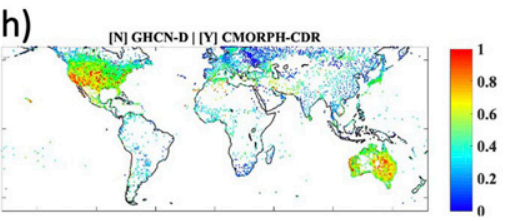

c)

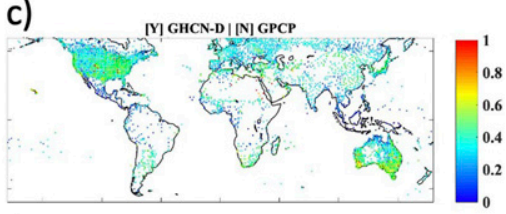

f)

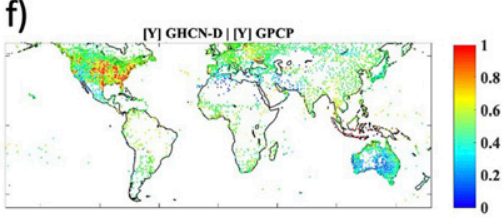

i)

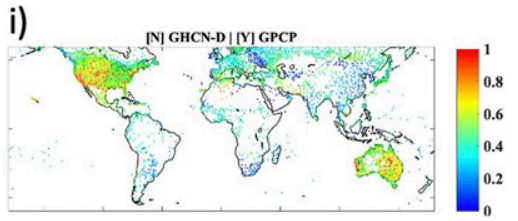

FIG. 7. Contingency analysis for daily rainfall retrieved by the different satellite CDR datasets with respect to in situ data from GHCND for (left) PERSIANN-CDR, (center) CMORPH-CDR, and (right) GPCP. Results indicate the normalized occurrences for (a)-(c) misses, (d)-(f) hits, and (g)-(i) false alarms. Data are for the year 2013.

United States. Here as well, the temporal mismatch between the in situ data accumulation and the SPPs is a possible explanation. Those characteristics are shared between the three SPPs. A closer look provides information in terms of differences between satellite products. PERSIANN-CDR presents a lower rate of misses (i.e., rain measured by the rain gauge without any rain detected by the satellite) (Fig. 7a) than the two other products CMORPH-CDR (Fig. 7b) and GPCP (Fig. 7c). This could indicate an increased sensitivity in detecting of low rainfall events by the satellite which relies on IR observations. This would be consistent with previous results that showed that PERSIANN-CDR had a higher number of rainy days when compared to CMORPH-CDR (Fig. 6i) and GPCP (Fig. 6g). Other noticeable divergence from the pattern shared by the three SPPs is the higher number of misses reported by CMORPH-CDR at higher latitudes over North America (Fig. 7b). Those high occurrences of missed precipitation are certainly due to the physical limitation of microwave sensors in detecting cold precipitation on snow covered surfaces (Tian et al. 2009; Beck et al. 2019a). This would be consistent with differences observed between CMORPH-CDR and the other two SPPs for annual and seasonal rainfall (Figs. 4 and 5).

The biases and correlations of the three SPPs with respect to in situ GHCN-D are presented in Fig. 8. Each SPP displays comparable biases for the daily rainfall when compared to GHCN-D. Globally, GPCP and PERSIANN-CDR present a positive bias (mean value of about $+10 \%$ ) while CMORPH-CDR has a negative bias (mean value of $-6 \%$ ) (Table 3 ). We note that GHCN-D stations are overwhelmingly located within the continental United States (about 69\%), followed by Australia (about 19\%); the remaining stations being located mostly in Europe and Asia. Similar values are found over CONUS, with a positive average bias for PERSIANN-CDR and GPCP $(+7 / 8 \%)$ and a negative average bias for CMORPH-CDR $(-6 \%)$. Over Australia, all SPPs indicate a positive bias with better statistics obtained with CMORPH-CDR (+4\%), when compared to GPCP $(+7 \%)$, and PERSIANN-CDR $(+15 \%)$. Those biases that could be qualified as satisfying are dampened by the relatively low correlation coefficients. Globally, CMORPH-CDR presents the highest average correlation for daily precipitation (0.41) when compared to PERSIANN-CDR

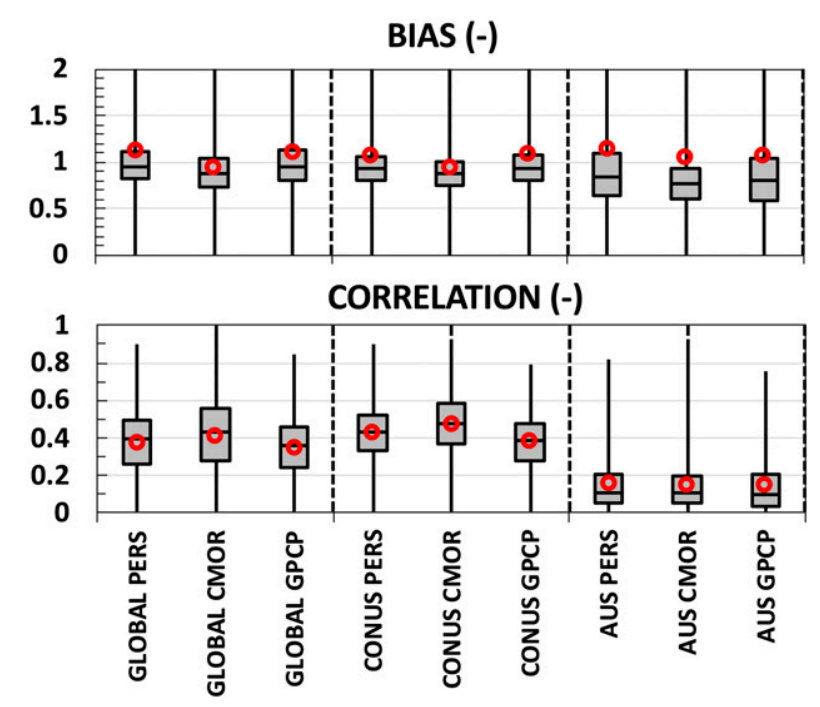

FIG. 8. (top) Bias and (bottom) correlation for daily precipitation with respect to in situ data from GHCN-D for PERSIANN-CDR (PERS), CMORPH-CDR (CMOR), and GPCP. Statistics are provided for all the GHCN-D stations over the entire globe (GLOBAL), and various subsets of GHCN-D stations including CONUS, and Australia (AUS). The lower, middle, and upper lines on the boxplot represent the 25th, 50th (median value), and 75th percentiles. The red circles represent the average values. Comparisons are for the year 2013 . 
TABLE 3. Median, mean, and standard deviation for bias and correlation (corr.) for daily precipitation for the three CDR datasets with respect to in-sit GHCN-D. Statistics are provided for the globe, CONUS, and Australia. Results are provided for the year 2013 for GHCN-D stations operating at least $90 \%$ of the time.

\begin{tabular}{|c|c|c|c|c|c|c|c|}
\hline \multirow[b]{2}{*}{ SPP } & \multirow[b]{2}{*}{ Statistic } & \multicolumn{2}{|c|}{ Global } & \multicolumn{2}{|c|}{ CONUS } & \multicolumn{2}{|c|}{ Australia } \\
\hline & & Bias & Corr. & Bias & Corr. & Bias & Corr. \\
\hline \multirow[t]{3}{*}{ GPCP } & Median & 0.95 & 0.36 & 0.93 & 0.38 & 0.79 & 0.10 \\
\hline & Mean & 1.11 & 0.35 & 1.08 & 0.38 & 1.07 & 0.15 \\
\hline & Std dev & 2.06 & 0.16 & 1.25 & 0.16 & 0.38 & 0.15 \\
\hline \multirow[t]{3}{*}{ PERSIANN-CDR } & Median & 0.95 & 0.39 & 0.93 & 0.43 & 0.83 & 0.11 \\
\hline & Mean & 1.12 & 0.37 & 1.07 & 0.43 & 1.15 & 0.16 \\
\hline & Std dev & 2.17 & 0.17 & 1.24 & 0.14 & 0.42 & 0.14 \\
\hline \multirow[t]{3}{*}{ CMORPH-CDR } & Median & 0.88 & 0.43 & 0.88 & 0.48 & 0.75 & 0.11 \\
\hline & Mean & 0.94 & 0.41 & 0.94 & 0.47 & 1.04 & 0.15 \\
\hline & Std dev & 1.56 & 0.20 & 1.51 & 0.16 & 0.36 & 0.14 \\
\hline GHCN-D Stations & & \multicolumn{2}{|c|}{$\cong 19200$} & \multicolumn{2}{|c|}{$\cong 13200$} & \multicolumn{2}{|c|}{$\cong 3650$} \\
\hline
\end{tabular}

(0.37) and GPCP (0.35). Over CONUS, all products present a higher correlation at $0.47,0.43$, and 0.38 for CMORPH-CDR, PERSIANN-CDR, and GPCP, respectively (Table 3). Over Australia, the correlation between GHCN-D stations and the three SPPs is extremely low between 0.14 and 0.16 , which could be an indication of temporal mismatch in daily accumulation between GHCN-D stations and SPPs. However, those evaluations are not completely independent because GHCN-D stations are incorporated in in situ datasets used for satellite bias adjustment procedures. Ideally, an evaluation of SPPs would require using in situ information that is not part of the biasadjustment procedure. This will be done next over CONUS with a comparison with USCRN stations.

\section{b. SPP evaluation over CONUS}

\section{1) CONTINGENCY ANALYSIS AND PERFORMANCE METRICS}

Figure 9 displays a contingency analysis at each USCRN station and associated regional networks (ALCRN, 4CCRN). The stations hourly rainfall was accumulated over $24-\mathrm{h}$ to match SPP daily rainfall (0000-0000 UTC). A point-to-pixel comparison is justified assuming that random sampling errors are negligible (Prat and Nelson 2015, 2020). Overall, CMORPH-CDR displays the higher ratio of matches with about $41 \%$ of events detected simultaneously by the satellite and the station (Fig. 9e). The other SPPs are slightly behind with 38\% for GPCP (Fig. 9f) and 37\% for PERSIANN-CDR (Fig. 9d) of simultaneous events recorded by the satellite and the gauge. Results are consistent with those obtained over CONUS with GHCN-D (Fig. 7).

Similarly to GHCN-D, there is a difference between east and west stations (Fig. 7). For USCRN stations located west of the longitude $104^{\circ} \mathrm{W}$, the ratio of events recorded simultaneously by SPPs and USCRN stations were 33\%, 31\%, and $32 \%$ for CMORPH-CDR, GPCP, and PERSIANN-CDR, respectively. For stations located east of longitude $104^{\circ} \mathrm{W}$, results were $49 \%, 44 \%$, and $43 \%$. As a sanity check, we compared SPPs daily precipitation (UTC) and USCRN daily accumulation considering the local standard time (LST). We noted that daily accumulation in UTC provided slightly better statistics than when considering daily accumulation expressed in local time. For instance, over CONUS, the percentage of events recorded simultaneously by the SPP and the USCRN stations are $39 \%, 37 \%$, and $36 \%$ for CMORPH-CDR, GPCP, and PERSIANN-CDR, respectively (not shown). However, those differences did not change the performance of each SPP with respect to the others. How these results would translate to other part of the world (i.e., Australia) is unclear at this point and beyond reach in the context of the current study. Please note that not all the stations have the same period of record. Stations located over the four corner states cover a 5-yr period (2009-14) instead of the 11-yr period (2007-18) in the case of most of the other USCRN stations. An analysis considering the period 2009-14 for all stations did not show any significant qualitative differences than when considering the period 2007-18 (not show). The most noticeable differences between the three SPPs are observed when rainfall is detected at the USCRN station only. Results show that PERSIANN-CDR (Fig. 9a) display a significant lower percentage of misses of $6 \%$, when compared to $19 \%$ for CMORPH-CDR (Fig. 9b) and $17 \%$ for GPCP (Fig. 9c). Conversely, PERSIANN-CDR (Fig. 9g) displays a higher percentage of false detection of about $57 \%$ on average, when compared to $40 \%$ and $46 \%$ for CMORPH-CDR (Fig. 9h) and GPCP (Fig. 9i), respectively. Overall, CMORPH-CDR presents the best results with the highest percentage of hits ( $41 \%)$, the lowest percentage of false detection $(40 \%)$, and the lowest ratio of events detected by satellite or the corresponding gauge only, yet at a high of $59 \%$.

Further performance evaluation is presented in Fig. 10 that includes metrics such as accuracy, false alarm ratio (FAR), probability of detection (POD), and probability of false detection (POFD). Overall, CMORPH-CDR displays the best results with an accuracy of 0.76 (perfect score of 1 : Fig. 10b), a FAR of 0.49 (perfect score of 1: Fig. 10e), a POD of 0.70 (perfect score of 1: Fig. 10h), and a POFD of 0.22 (perfect score of 0: Fig. 10k). GPCP comes second, with 0.73, 0.55, 0.69, and 0.26 for accuracy (Fig. 10c), FAR (Fig. 10f), POD (Fig. 10i), and POFD (Fig. 101), respectively. While, PERSIANN-CDR, displays a better POD of 0.86 (Fig. 10g), it presents lower values of accuracy of 0.66 (Fig. 10a), and higher values of FAR of 0.60 (Fig. 10d) and POFD of 0.41 (Fig. 10j). Considering 
a)

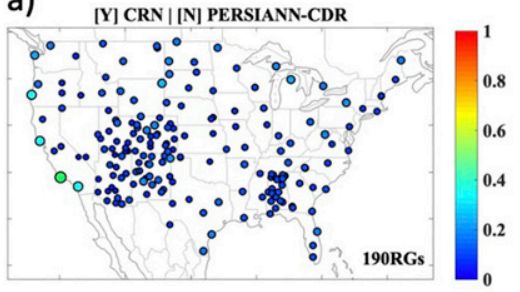

d)

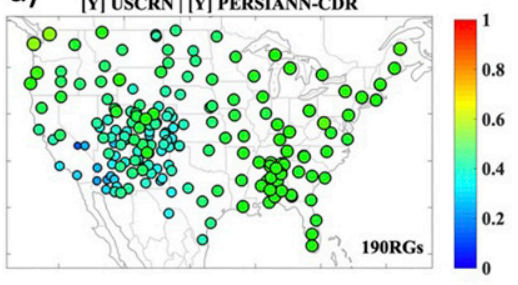

g)

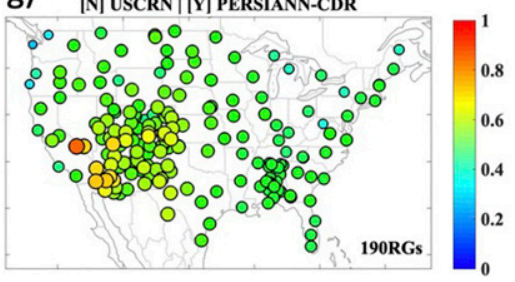

b)

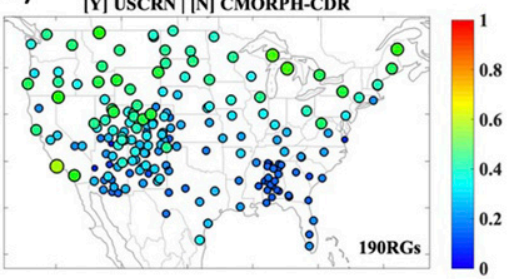

e)

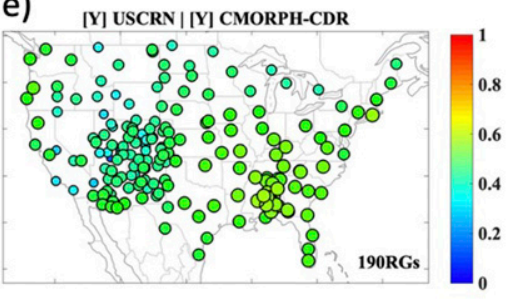

h)

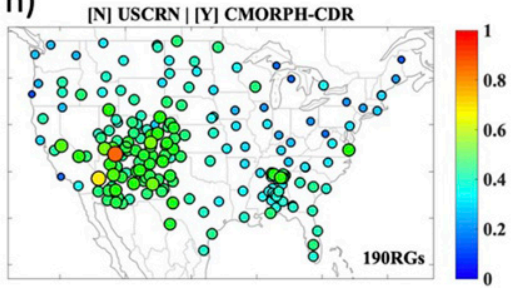

c)

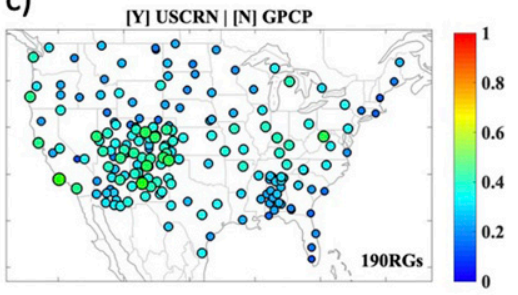

f)

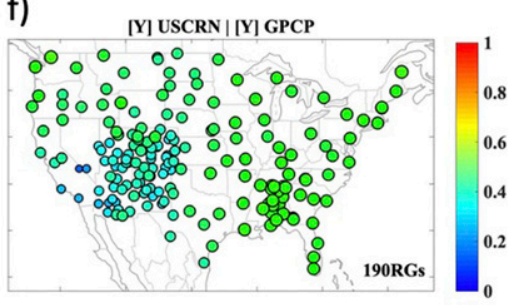

i)

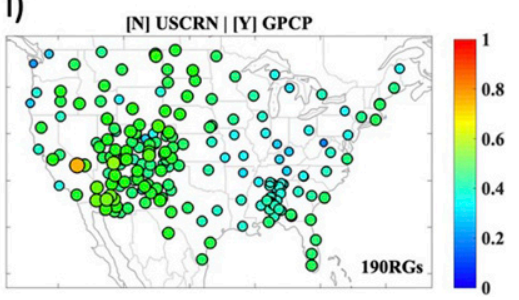

FIG. 9. Contingency analysis for daily rainfall retrieved by the different satellite CDR datasets with respect to in situ data from USCRN for (left) PERSIANN-CDR, (center) CMORPH-CDR, and (right) GPCP. Results indicate the normalized occurrences for (a)-(c) satellite misses, (d)-(f) hits, and (g)-(i) false alarms. For most USCRN stations, including for the ALCRN regional network, the analysis covers the years 2007-18. For the stations of the U.S. Regional Climate Reference Network over the four corner states, the analysis covers the years 2009-14.

those metrics, PERSIANN-CDR tends to have a lower threshold for detection when compared to the other SPPs. CMORPH-CDR and to a lesser extend GPCP represent a better compromise between hits and misses. In terms of spatial distribution, SPP performances are better in the east than in the west (east/west of longitude $104^{\circ} \mathrm{W}$ ) with CMORPH-CDR presenting better statistics with accuracies of 0.77 (east) and 0.74 (west), FARs 0.40 of (east) and 0.57 (west), PODs of 0.75 (east) and 0.65 (west), and POFDs of 0.21 (east) and 0.23 (west). The SPPs present the worst results over the Rocky Mountains and the four corners region. For CMORPH-CDR there are noticeable differences in terms of SPP performances along a northward direction as indicated by a decrease in the POD from about 0.75 for stations located south of $40^{\circ} \mathrm{N}$ to 0.57 for stations located north $40^{\circ} \mathrm{N}$ (Fig. 10h). Like for GHCN-D (Fig. 7), the decrease in performance (POD) along a northward direction can possibly be linked to the challenges in retrieving cold precipitation (Tian et al. 2009; Beck et al. 2019a). This was confirmed by considering separately the cold (DJF) and warm (JJA) seasons. While there was not significant variation of the POD with respect to the latitude during the warm season, we noted an important decrease in the POD in a northward direction during the cold season (not shown).

To check the influence of each satellite sensitivity at a low rain rate, we considered a threshold of $0.2 \mathrm{~mm} \mathrm{day}^{-1}$, which is the same value than the daily limit of USCRN stations (not shown). We note a slight improvement in the percentages of cases observed simultaneously at both the satellite and the station. Those results are $43 \%, 38 \%$, and $38 \%$ for CMORPH-CDR, GPCP, and PERSIANN-CDR, respectively, to be compared by $41 \%, 38 \%$, and $37 \%$ (Fig. 9). The most important differences are reported for the events observed by one of the other sensors (SPPs or USCRN). There is a significant decrease in the numbers of events observed only by the SPP $(2 \%-7 \%)$ which translate into an increase in the number observed at the ground only ( $1 \%-4 \%)$ (not shown). Regarding the other statistics (accuracy, POD, FAR, POFD), all three SPPs present an improvement (increase) for the accuracy $(2 \%-4 \%)$, an improvement (decrease) for the FAR (from $-1 \%$ to $-4 \%$ ) and the POFD $(4 \%-6 \%)$. Conversely, the POD displays lower values (from $-2 \%$ to $-7 \%$ ) (not shown).

\section{2) SPP QUANTITATIVE EVALUATION}

Biases and Pearson correlation coefficients are presented in Fig. 11. When computed conditionally, that is for rainfall simultaneously recorded by the satellite and at the collocated USCRN station, average biases for CMORPH-CDR, GPCP, and PERSIANN-CDR are 0.94 (Fig. 11b), 0.92 (Fig. 11c), and 0.71 (Fig. 11a), respectively. Noticeable differences are found 
a)

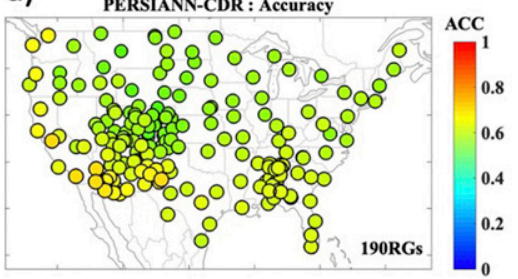

d)

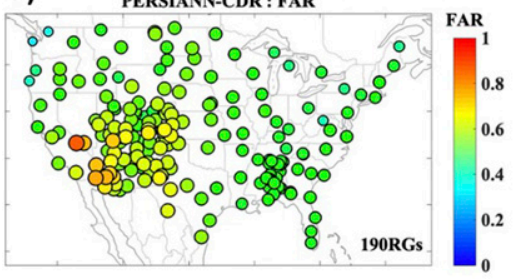

g)

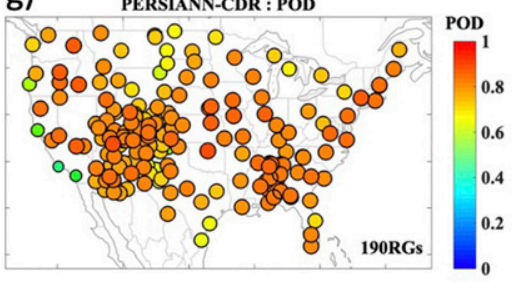

j)

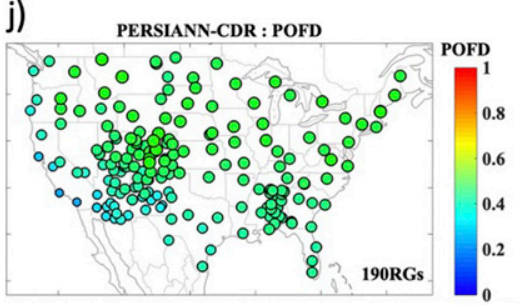

b)

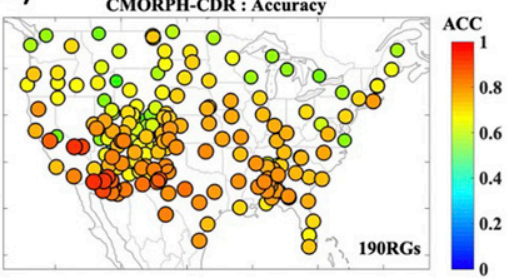

e)

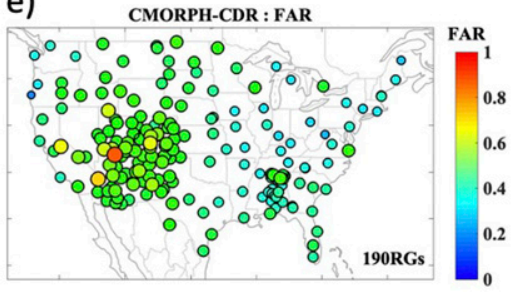

h)

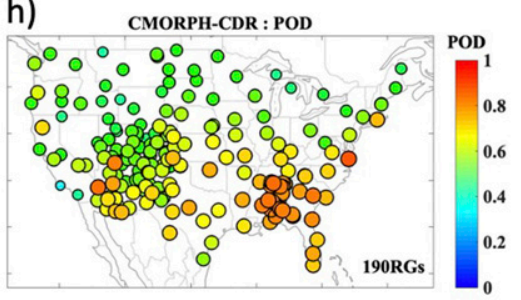

k)

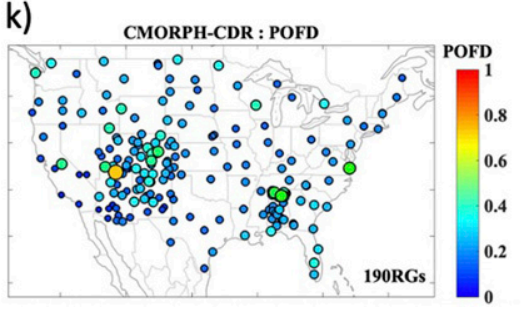

c)

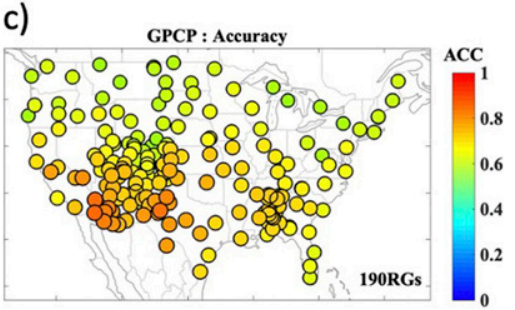

f)
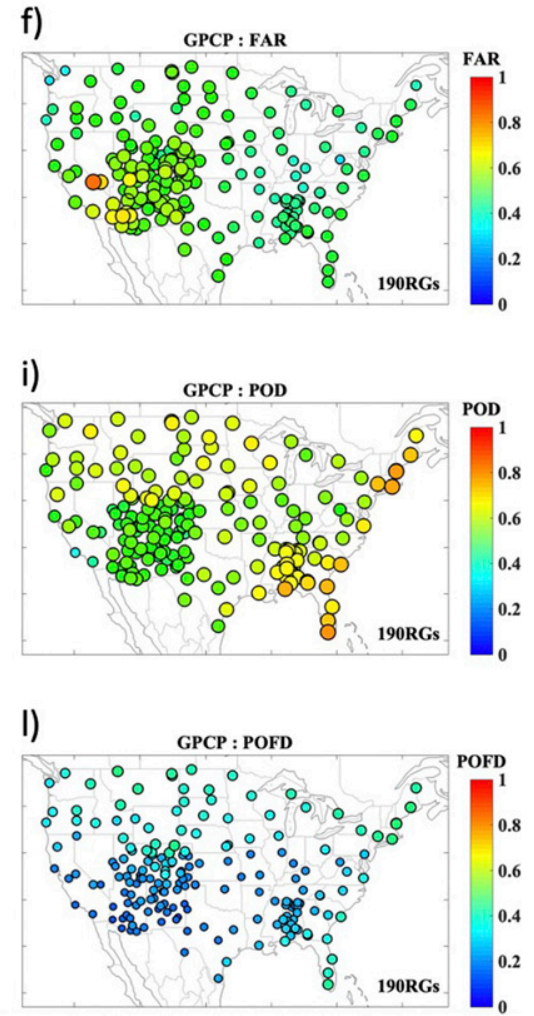

FIG. 10. Performance comparison for (left) PERSIANN-CDR, (center) CMORPH-CDR, and (right) GPCP with respect to USCRN. For most USCRN stations including for the ALCRN regional network, the analysis covers the years 2007-18. For the stations of the U.S. Regional Climate Reference Network over the four corner states, the analysis covers the years 2009-14. The metrics for performance assessment are (a)-(c) accuracy, (d)-(f) POD, (g)-(i) FAR, and (j)-(l) POFD. The metrics are defined as follows: accuracy $=(\mathrm{YY}+\mathrm{NN}) /$ total, $\mathrm{POD}=\mathrm{YY} /(\mathrm{YY}+\mathrm{YN}), \mathrm{FAR}=\mathrm{NY} /(\mathrm{YY}+\mathrm{NY})$, and POFD $=\mathrm{NY} /(\mathrm{NN}+\mathrm{NY})$. The first letter $(\mathrm{Y}$ : yes; N: no) indicates the value at the USCRN station, and the second indicates the value at the corresponding SPP pixel.

over the Rockies where PERSIANN-CDR presents negative biases $($ ratio $<1$ ) while GPCP and CMORPH-CDR present positive biases (ratio $>1$ ). Correlation coefficients are an average of $0.55,0.42$, and 0.36 for CMORPH-CDR (Fig. 11e), PERSIANN-CDR (Fig. 11d), and GPCP (Fig. 11f), respectively.

When computed unconditionally (i.e., over all rainfall events), biases indicate that PERSIANN-CDR and GPCP tend to overestimate total precipitation with average biases of 1.12 for PERSIANN-CDR (Fig. 11g) and 1.20 for GPCP (Fig. 11i). Those values are very close to the values reported for PERSIANN-CDR and GPCP over CONUS where the SPPs are compared to Stage IV data (Beck et al. 2019a). For CMORPH-CDR the value of the bias is close to unity (0.96) and comparable to the previous value (0.94) obtained for simultaneous events only
(Fig. 11h). This is a similar result than the average value reported elsewhere (Beck et al. 2019a). There is an improvement for the correlation coefficient with average values of the correlation coefficients of $0.62,0.51$, and 0.41 for CMORPH-CDR (Fig. 11k), PERSIANN-CDR (Fig. 11j), and GPCP (Fig. 111), respectively. Those results are consistent with the study above that obtained an average correlation coefficient of approximately 0.75, 0.6, and 0.52 for CMORPH-CDR, PERSIANN-CDR, and GPCP, respectively, over CONUS using Stage IV as a reference. Spatially, we note that PERSIANN-CDR (Fig. 11g) and GPCP (Fig. 11i) overestimate the amount of precipitation over the western United States (Rockies). Finally, CMORPH-CDR presents higher correlation coefficient over the Southeast, and along the East and West Coasts (Fig. 11k). Again, those results are consistent 
a)

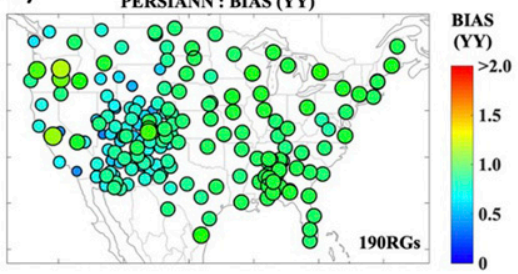

d)

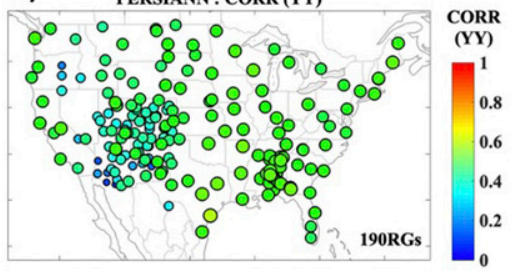

g)

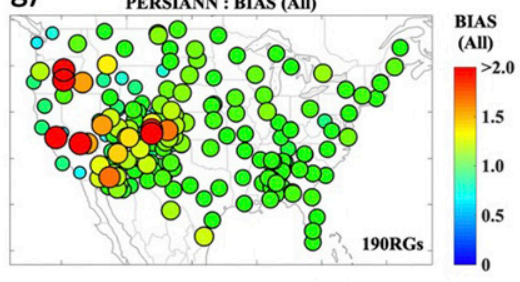

j)

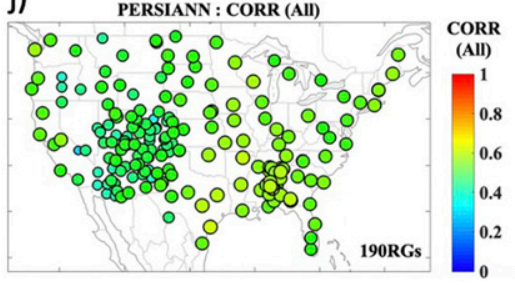

b)

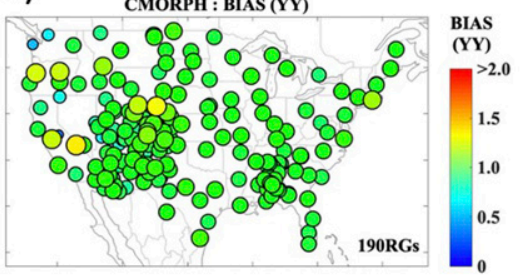

e)

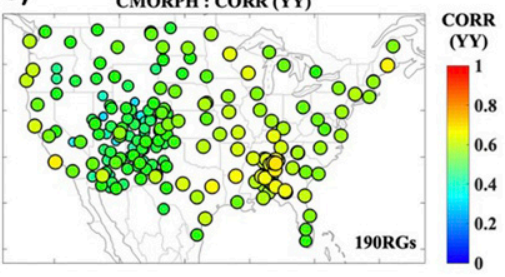

h)

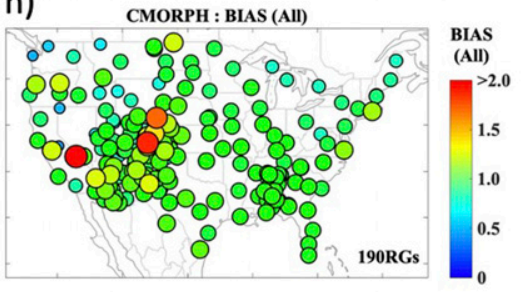

k)

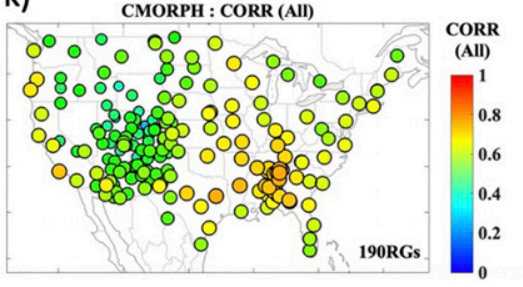

c)

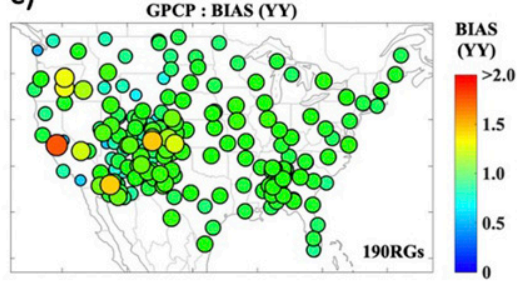

f)

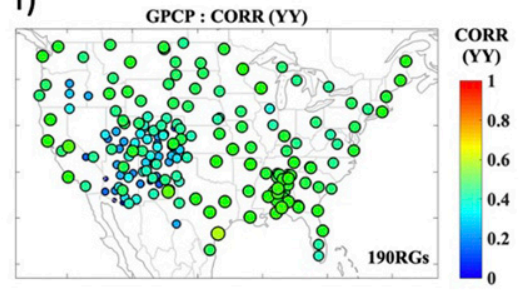

i)

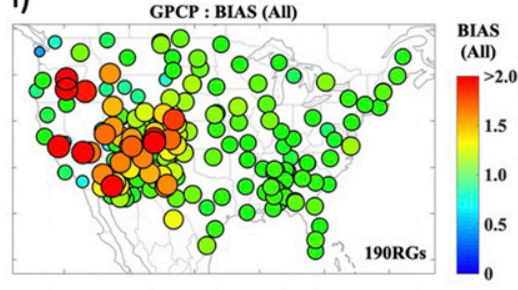

I)

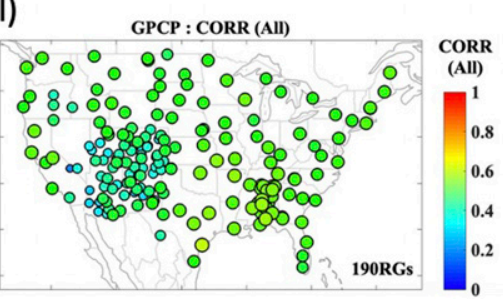

FIG. 11. Bias and Pearson's correlation coefficient for daily precipitation with respect to USCRN in situ data for (left) PERSIANNCDR, (center) CMORPH-CDR, and (right) GPCP. For most USCRN stations including for the ALCRN regional network, the analysis covers the years 2007-18. For the stations of the U.S. Regional Climate Reference Network over the four corners states, the analysis covers the years 2009-14. Bias and correlations are computed conditionally [i.e., (a)-(f) considering only nonzeros simultaneously at the USCRN station and at the corresponding satellite pixel, YY] and (g)-(l) unconditionally (i.e., over the entire period of record including zeros and nonzeros alike).

with previous study that reported a similar lower performance in the western United States due to a more complex topography (Beck et al. 2019a). Overall, CMORPH-CDR presents better statistics over CONUS for simultaneous rainfall events (conditional) and for all rainfall events (unconditional) with a slight rainfall underestimation (biases of 0.94 and 0.96 , respectively) and better correlation coefficients (correlation of 0.55 and 0.62 , respectively). PERSIANN-CDR and GPCP are found to underestimate simultaneous events at the satellite and at the USCRN station (biases of 0.71 and 0.92, respectively) and overestimate total rainfall accumulation (biases of 1.12 and 1.20, respectively). The IR-based GPCP and PERSIANN-CDR have a higher sensitivity to light rainfall detection. This was illustrated by the highest values of POD and at the same time the important values of POFD for
PERSIANN-CDR (Fig. 10). An analysis performed by applying a daily threshold of $0.2 \mathrm{~mm}^{-1 a y}{ }^{-1}$ on PERSIANN-CDR, did not show significant changes in terms of biases and correlations (not shown). Overall, those results are consistent with others (Beck et al. 2019a), although the range of values for biases and correlation coefficients are shifted toward lower values in our case. There are two possible reasons for this: first, we are evaluating the SPPs over a much lower number of samples (USCRN stations versus grid points of the Stage IV mosaic). Second, Stage IV includes a bias-adjustment procedure that uses the same gauge information (GHCN-D) used in SPPs' bias adjustment [see Nelson et al. (2016) for a description of Stage IV data]. Therefore, a better performance with respect to Stage IV is to be expected for SPPs when compared to their performance with respect to USCRN since 

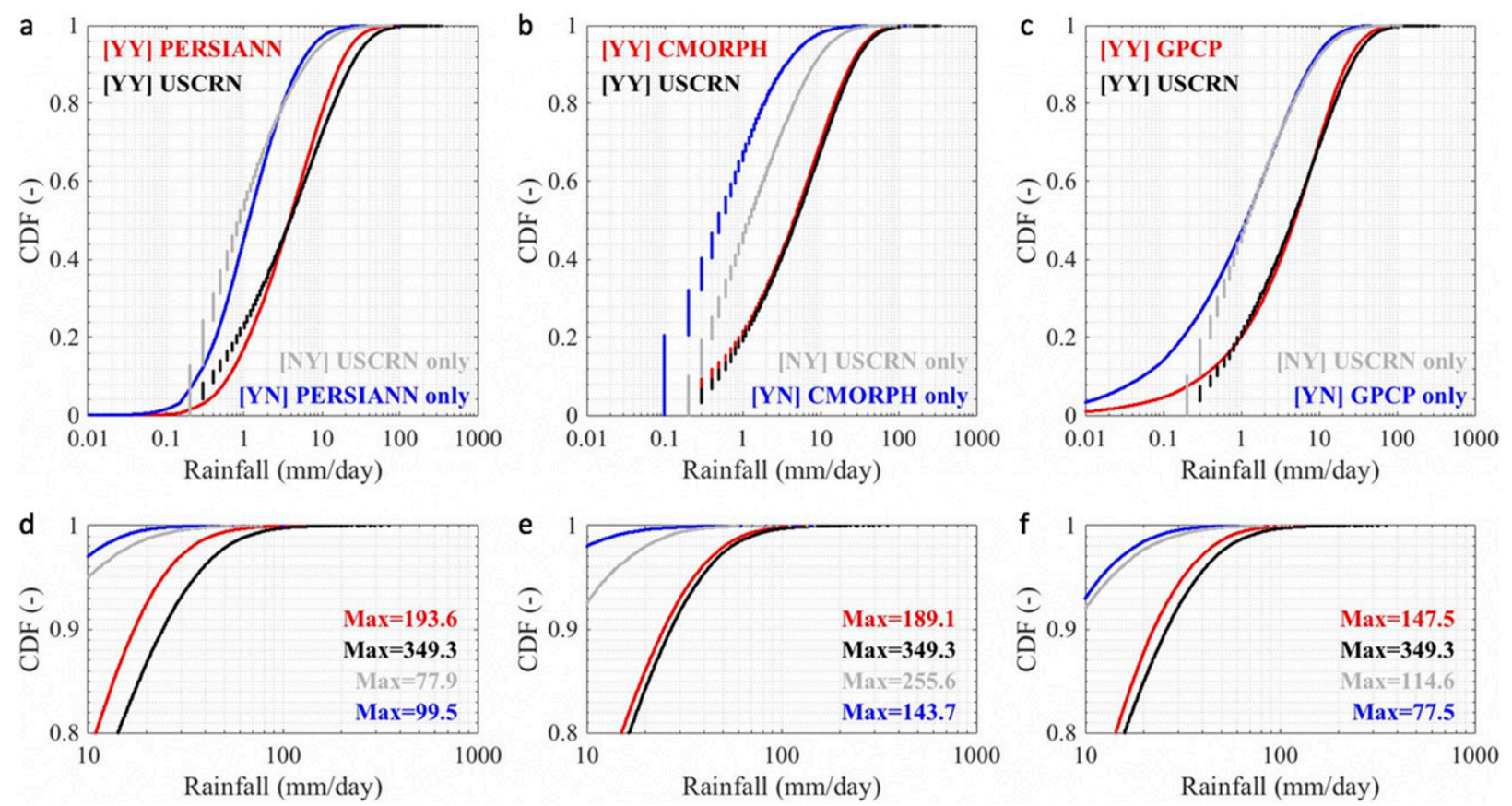

FIG. 12. (a)-(c) Cumulative distribution function of daily rainfall for events observed simultaneously by all USCRN stations (black) and SPPs (red), rainfall events observed only at the USCRN stations (gray), and rainfall events observed only by each SPP (blue): (a) PERSIANN-CDR, (b) CMORPH-CDR, and (c) GPCP. (d)-(f) As in (a)-(c), but with a zoom-in above the 80th percentile on the right-hand side of the spectra for PERSIANN-CDR, CMORPH-CDR, and GPCP. Data are for the period 2007-18 over CONUS.

both datasets (SPPs, Stage IV) rely on similar in situ data (GHCN-D).

\section{3) DAILY RAINFALL DISTRIBUTION}

Figure 12 displays the cumulative distribution functions for daily rainfall for each SPP compared to corresponding USCRN stations. For daily events observed simultaneously by the satellite (red line) and at the USCRN station (black line), CMORPH-CDR present a better agreement (Fig. 12b) than GPCP (Fig. 12c) and PERSIANN-CDR (Fig. 12a). Both distributions (CMORPH-CDR, USCRN) are comparable throughout the daily rainfall range. CMORPH-CDR underestimates daily rainfall both at lower rain rates (less than 25 th percentile: Fig. 12b) and at higher rain rates (above 80th percentile: Fig. 12f). For GPCP, the distribution presents a significant number (about 10\%) of low rainfall events (under $0.2 \mathrm{~mm} \mathrm{day}^{-1}$ ), which is below USCRN threshold (red line Fig. 12c). There is a relatively good agreement at moderate rain rates between the 25 th $\left(1.44 \mathrm{~mm} \mathrm{day}^{-1}\right)$ and 75 th $\left(11.91 \mathrm{~mm} \mathrm{day}^{-1}\right)$ percentiles (Table 4). At higher rain rates (above 80th percentile), we observe a significant underestimation by GPCP with respect to USCRN stations (Fig. 12f). For PERSIANN-CDR, satellite and USCRN distributions present more differences with a relatively good agreement limited around the median rain rate; that is between the 40th and 60th percentiles (Fig. 12a). Below the 40th percentile, PERSIANN-CDR tends to overestimate daily rainfall with higher daily rain rates than for USCRN (Fig. 12a). Finally, like for the other two SPPs, PERSIANN-CDR displays a significant underestimation at higher rain rates above the 80th percentile (Fig. 12d). Table 4 reports the statistics of the comparison of each SPP with USCRN stations (for simultaneous SPP and in situ daily events, for events at the satellite or the USCRN station only, and for the entire distributions). Figure 12 also displays the distributions of daily events observed by the satellite only (blue line) and at the USCRN station only (gray line). We note that a lot of daily rain rates observed only by GPCP are characterized by low accumulation (blue line Fig. 12c). We find that $20 \%$ of those events are below the USCRN threshold $\left(0.2 \mathrm{~mm} \mathrm{day}^{-1}\right)$. For CMORPH-CDR, the events observed only by the satellite are characterized by lower rain rates than events observed only at USCRN stations (Fig. 11b). Finally, results show that the number of events observed at the SPP only (false alarm), are about twice as much as the events observed at the USCRN station only (misses) for CMORPH-CDR and GPCP, and about seven time more for PERSIANN-CDR (Table 4).

Figure 13 displays a comparison between SPPs and in situ USCRN. All SPPs indicate a higher number of rainy days (Figs. 13a-c) when compared to USCRN stations (Fig. 13d). The ratio of rainy day recorded at the USCRN is $26 \%$ to be compared with $52 \%, 33 \%$, and $37 \%$ for PERSIANN-CDR, CMORPH-CDR, and GPCP, respectively, over CONUS. This ratio becomes $49 \%, 29 \%$, and $31 \%$ for PERSIANN-CDR, CMORPH-CDR, and GPCP, respectively, when considering only SPP records above $0.2 \mathrm{~mm} \mathrm{day}^{-1}$ (not shown). All SPPs (Figs. 13e-g) are found to underestimate the average daily precipitation when compared to USCRN (Fig. 13h). The average daily rain rate over the USCRN stations is $7.24 \mathrm{~mm}_{\text {day }}{ }^{-1}$ to be 
TABLE 4. Statistics of daily rainfall distributions derived from the USCRN and SPPs comparison over CONUS for the period 2007-18. All USCRN stations are considered. Results are for a conditional comparison $(R>0)$ and for an unconditional comparison $(R \geq 0)$.

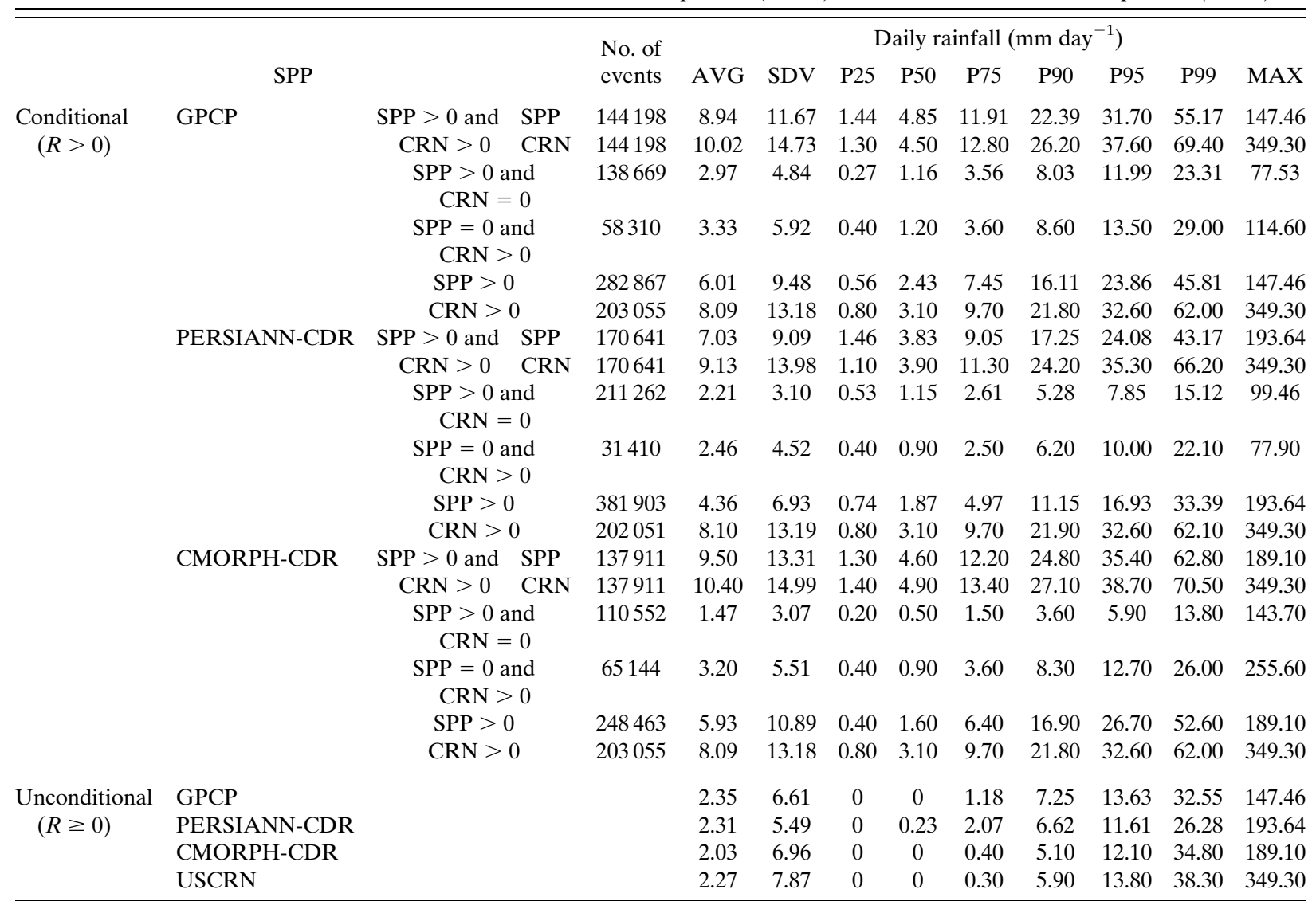

compared with $3.85,5.17$, and $5.43 \mathrm{~mm}$ day $^{-1}$; those are differences of $-47 \%,-29 \%$, and $-25 \%$ for PERSIANN-CDR, CMORPH-CDR, and GPCP, respectively. All SPPs underestimate average daily precipitation with CMORPH-CDR and GPCP displaying comparable results, while PERSIANN-CDR display significantly lower average daily precipitation than the two other SPPs. Values of the 95th percentiles (Figs. 13i-1) and maximum daily rainfall (Figs. 13m-p) show that all three SPPs underestimate extreme precipitation when compared to USCRN. Of the three SPPs, CMORPH-CDR is the closest of in situ USCRN data. For all USCRN stations, the 95th percentile is $32.6 \mathrm{~mm} \mathrm{day}^{-1}$ which is higher than $26.7 \mathrm{~mm} \mathrm{day}^{-1}$ for CMORPH-CDR (-19\%), $23.86 \mathrm{~mm} \mathrm{day}^{-1}$ for GPCP $(-24 \%)$, and $16.93 \mathrm{~mm} \mathrm{day}^{-1}$ for PERSIANN-CDR (-48\%) (Table 4). While PERSIANN-CDR has lower values for the 95th and 99th percentiles than the two other SPPs, it displays the highest maximum daily rainfall at $193.64 \mathrm{~mm}_{\text {day }}{ }^{-1}$, which is $44 \%$ lower than the maximum of $349.3 \mathrm{~mm}^{\text {day }}{ }^{-1}$ reported by USCRN stations (Table 4).

\section{Summary and conclusions}

Three SPPs that are part of the NOAA Climate Data Record Program have been evaluated over their period of record. The findings can be summarized as follows:
- Globally, in terms of average precipitation, PERSIANN-CDR and GPCP-Daily remain relatively close due to the fact that GPCP-Monthly is used for PERSIANN-CDR bias adjustment. Over ocean, the three SPPs present comparable daily averages because both PERSIANN-CDR and CMORPHCDR use GPCP for calibration with differences below $1 \%$. Over land, PERSIANN-CDR and GPCP remain relatively close for the same raison with differences within $3 \%$, while CMORPH-CDR displays a lower rainfall average between $-14 \%$ and $-19 \%$ when compared to PERSIANNCDR and GPCP. The most important differences are found at higher latitudes in the Northern Hemisphere.

- During the cold/warm months, PERSIANN-CDR and GPCP display similar average daily precipitation with differences below $1 \%$ over land. CMORPH-CDR shows systematically lower daily average rainfall than the two other SPPs with differences ranging from $-8 \%$ for July in the Southern Hemisphere to $-38 \%$ for January in the Northern Hemisphere (cold season).

- The differences in terms of daily maximum rainfall are important between the three SPPs, with CMORPH-CDR and GPCP presenting the highest and the lowest daily maximum rainfall, respectively. Differences were also significant when looking at the number of rainy days. Over ocean and over northern Europe, GPCP presents more rainy 
a)

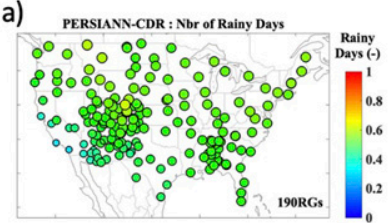

e)

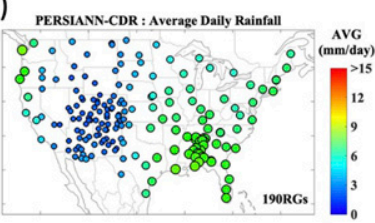

i)

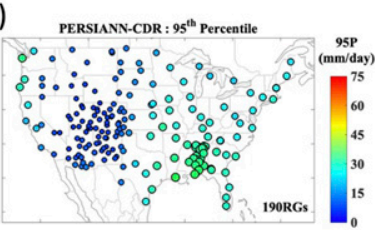

m)

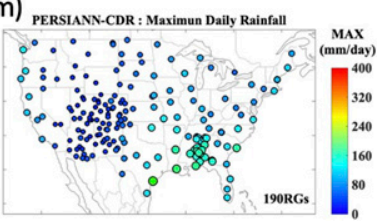

b)

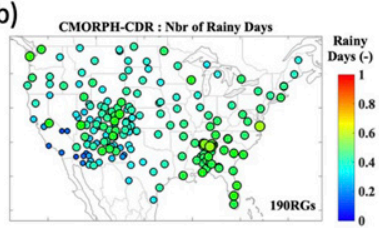

f)
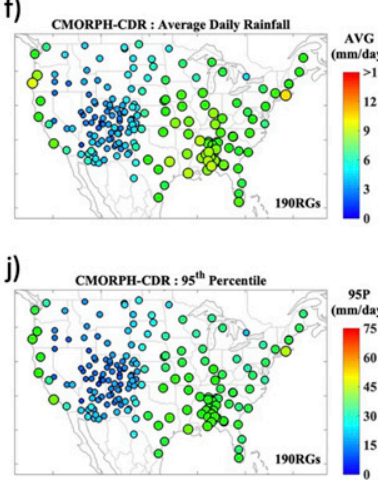

n)

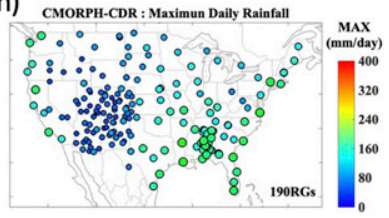

c)

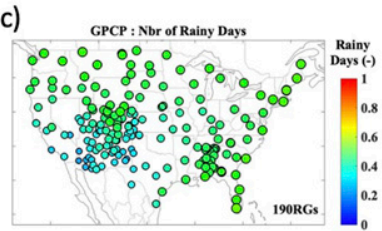

g)

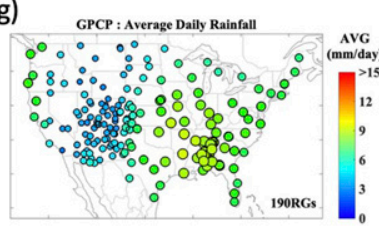

k)

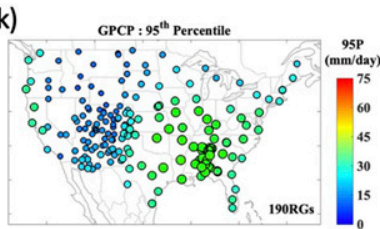

o)

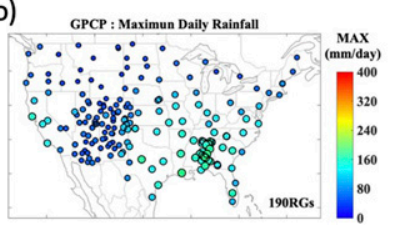

d)

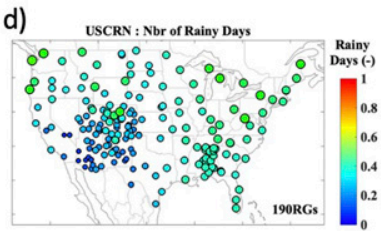

h)

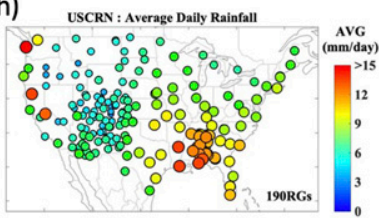

I)

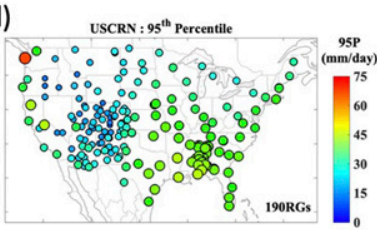

p)

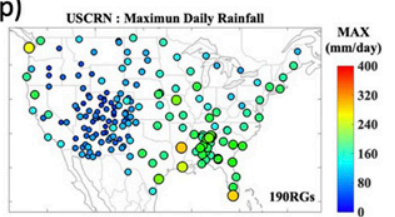

FIG. 13. (a)-(d) Percentage of rainy days, and (e)-(h) value of the average daily rainfall, (i)-(l) 95th percentile, and (m)-(p) maximum daily rainfall retrieved from the CDR SPPs: (first column) PERSIANN-CDR, (second column) CMORPH-CDR, and (third column) GPCP, and (fourth column) in situ USCRN for the period 2007-18 for most of the USCRN and ALCRN stations and for the period 200914 for the stations of the U.S. Regional Climate Reference Network over the four corner states.

days than the two other SPPs, while over land PERSIANNCDR had the highest number of rainy days. The most important differences are observed for CMORPH-CDR characterized by a lower number of rainfall days over land in particular at higher latitudes where microwave retrievals are known to be deficient in capturing precipitation over snow covered surface in winter. In terms of rainfall distribution, despite spatial differences in the number of rainy days and in the values of the daily maximum rainfall, PERSIANN-CDR and GPCP have similar average rainfall due to the bias adjustment. With a lower number of rainfall days, and despite a precipitation distribution skewed toward higher rain rates, CMORPH-CDR presents lower average rainfall.

- A contingency analysis with respect to GHCN-D showed that each SPP presents the same spatial distribution and comparable statistics for hits, misses, and false alarm. The comparison with GHCN-D showed that the three SPPs had comparable biases, although CMORPH-CDR presented a slightly better overall agreement with GHCN-D. A global comparison with GHCN-D stations at the daily scale is, however, delicate due to an absence of satisfying coverage over large land areas and gauges mostly located in North America, Australia, and Europe. Over Australia, the correlation between SPPs and GHCN-D were very low and tend to indicate a mismatch in daily accumulation period between the in situ data and the satellites.
- The independent evaluation performed over CONUS using USCRN stations showed that CMORPH-CDR performs better in terms of accuracy, FAR, POD, and POFD. PERSIANN-CDR displays higher FAR values than the two other SPPs. CMORPHCDR presents smaller bias and higher correlation; both conditionally and unconditionally, than the other SPPs. The comparison of the daily rainfall events between CMORPHCDR and USCRN shows that this agreement is consistent throughout the entire distribution (from low to higher rainfall rates). For GPCP and PERSIANN-CDR, this agreement is mostly satisfying in the median daily rainfall range. It was noted that each SPP performance was noticeably better over the eastern United States when compared to the western United States.

- Overall, CMORPH-CDR presents a better performance than the two other SPPs. For accumulation period greater than the day (i.e., week, month, years), all SPPs perform satisfyingly, which makes them suitable for long term hydrological and hydroclimatological applications. When looking at daily events, results indicated that CMORPH-CDR performs better than the two other SPPs when considering an ensemble of statistical metrics such as accuracy, POD, POFD, FAR, bias, correlation, and percentile values. The underlying physical principle of CMORPH-CDR based on microwave retrieval, explains the improved performance when compared to the two other SPPs based on IR measurements. All SPPs are 
found to miss a sizeable number of rainfall events observed at the ground (10\%-20\% on average) and falsely detect events that are not observed at the ground $(40 \%-50 \%$ on average). While all SPPs tend to underestimate extreme rainfall (above 90th percentile), CMORPH-CDR presents a better agreement with USCRN stations with differences of about $-20 \%$ at the 90th percentile.

Acknowledgments. This research was supported by NOAA through the Cooperative Institute for Satellite Earth System Studies (CISESS) under Cooperative Agreement NA19NES4320002 (since July 2019) and through the Cooperative Institute for Climate and Satellites-North Carolina (CICS-NC) under Cooperative Agreement NA14NES432003 (up to June 2019).

Data availability statement. All Climate Date Records satellite precipitation products used in this study are openly available through the NOAA/NCEI/CDR portal at https:// www.ncdc.noaa.gov/cdr. The PERSIANN-CDR dataset (Ashouri et al. 2015) can be found at https://www.ncdc.noaa.gov/cdr/ atmospheric/precipitation-persiann-cdr. The GPCP daily dataset (Adler et al. 2017b) can be found at https://www.ncdc.noaa.gov/ cdr/atmospheric/precipitation-gpcp-daily. The CMORPH-CDR dataset (Xie et al. 2017) can be found at https:/www.ncdc.noaa.gov/ cdr/atmospheric/precipitation-cmorph. The GHCN-D data (Menne et al. 2012) can be found at https://www.ncei.noaa.gov/data/globalhistorical-climatology-network-daily/. The hourly USCRN data used for evaluation over CONUS (Diamond et al. 2013) can be found at https://www1.ncdc.noaa.gov/pub/data/uscrn/products/ hourly $02 /$.

\section{APPENDIX}

\section{List of Acronyms}

$\begin{array}{ll}\text { 4CCRN } & \begin{array}{l}\text { Four Corner (4C) Regional Climate Reference } \\ \text { Network }\end{array} \\ \text { ALCRN } & \begin{array}{l}\text { Alabama Regional Climate Reference Network } \\ \text { Advanced Microwave Scanning Radiometer } \\ \text { for EOS }\end{array} \\ \text { AMSU-A } & \text { Advanced Microwave Sounding Unit-A } \\ \text { AMSU-B } & \text { Advanced Microwave Sounding Unit-B } \\ \text { AVHRR } & \text { Advanced Very High Resolution Radiometer } \\ \text { CAMS } & \text { Climate Anomaly Monitoring System } \\ \text { CDR } & \text { Climate Data Record } \\ \text { CLW } & \text { Cloud liquid water } \\ \text { CMORPH } & \text { CPC morphing technique } \\ \text { CONUS } & \text { Conterminous United States } \\ \text { CPC } & \text { NOAA/Climate Prediction Center } \\ \text { DEM } & \text { Digital elevation model } \\ d z / d x & \text { Longitudinal components of slope (DEM) } \\ d z / d y & \text { Latitudinal components of slope (DEM) } \\ E & \text { Exposure to orography (DEM) } \\ \text { ENSO } & \text { El Niño-Southern Oscillation } \\ \text { GEOS } & \text { Geostationary Operational Environmental } \\ \text { GHCN-D } & \text { Satellite } \\ & \text { Global Historical Climatology Network-Daily }\end{array}$

\author{
GMI GPM Microwave Imager \\ GPCC Global Precipitation Climatology Centre \\ GPCP Global Precipitation Climatology Project \\ GPM Global Precipitation Mission \\ GridSat-B1 Geostationary IR Channel Brightness Temperature \\ Gridded Satellite \\ ICDR Interim Climate Data Record \\ IR Infrared \\ LST Local standard time \\ MHS Microwave Humidity Sounder \\ OLR NOAA Interpolated Outgoing Longwave \\ Radiation \\ PERSIANN Precipitation Estimation from Remotely \\ Sensed Information Using Artificial Neural \\ Networks \\ PERSIANN- PERSIANN-Climate Data Record \\ CDR \\ PMW Passive microwave \\ SSM/I Special Sensor Microwave Imager \\ SSMIS Special Sensor Microwave Imager/Sounder \\ TMI TRMM Microwave Imager \\ TOVS TIROS Operational Vertical Sounder \\ USCRN U.S. Climate Reference Network \\ $z \quad$ Elevation (DEM)
}

\section{REFERENCES}

Adler, R., M. Sapiano, and J.-J. Wang, 2017a: Precipitation Global Precipitation Climatology Project (GPCP) Monthly (01B-34). Climate Algorithm Theoretical Basis Doc., revision 2, 33 pp., https://www1.ncdc.noaa.gov/pub/data/sds/cdr/CDRs/ Precipitation_GPCP-Monthly/AlgorithmDescription_01B-34.pdf.

$\longrightarrow,-$, and $—$, 2017b: Global Precipitation Climatology Project (GPCP) Daily Analysis Precipitation - GPCP Daily CDR. Climate Algorithm Theoretical Basis Doc., 21 pp., https://www1.ncdc.noaa.gov/pub/data/sds/cdr/CDRs/Precipitation_ GPCP-Daily/AlgorithmDescription_01B-35.pdf.

_- and Coauthors, 2018: The Global Precipitation Climatology Project (GPCP) monthly analysis (new version 2.3) and a review of 2017 global precipitation. Atmosphere, 9, 138, https:// doi.org/10.3390/atmos9040138.

AghaKouchak, A., A. Behrangi, S. Sorooshian, K. Hsu, and E. Amitai, 2011: Evaluation of satellite-retrieved extreme precipitation rates across the central United States. J. Geophys. Res., 116, D02115, https://doi.org/10.1029/2010JD014741.

- A. Mehran, H. Norouzi, and A. Behrangi, 2012: Systematic and random error components in satellite precipitation data sets. Geophys. Res. Lett., 39, L09406, https://doi.org/10.1029/ 2012 GL051592.

Ashouri, H., K. L. Hsu, S. Sorooshian, D. K. Braithwaite, K. R. Knapp, L. D. Cecil, B. R. Nelson, and O. P. Prat, 2015: PERSIANN-CDR daily precipitation climate data record from multisatellite observations for hydrological and climate studies. Bull. Amer. Meteor. Soc., 96, 69-83, https://doi.org/ 10.1175/BAMS-D-13-00068.1.

Barry, R. G., 1992: Mountain Weather and Climate. 2nd ed. Routledge, $402 \mathrm{pp}$.

Beck, H. E., and Coauthors, 2017: Global-scale evaluation of 22 precipitation datasets using gauge observations and hydrological modeling. Hydrol. Earth Syst. Sci., 21, 6201-6217, https://doi.org/10.5194/hess-21-6201-2017. 
_ - and Coauthors, 2019a: Daily evaluation of 26 precipitation datasets using Stage-IV gauge-radar data for the CONUS. Hydrol. Earth Syst. Sci., 23, 207-224, https://doi.org/10.5194/ hess-23-207-2019.

— , E. F. Wood, M. Pan, C. K. Fisher, D. G. Miralles, A. I. J. M. van Dijk, T. R. McVicar, and R. F. Adler, 2019b: MSWEP V2 global 3-hourly $0.1^{\circ}$ precipitation: Methodology and quantitative assessment. Bull. Amer. Meteor. Soc., 100, 473-500, https://doi.org/10.1175/BAMS-D-17-0138.1.

Burns, J. I., 1953: Small-scale topographic effects on precipitation distribution in San Dimas experimental forest. Trans. Amer. Geophys. Union, 34, 761-768, https://doi.org/10.1029/ TR034i005p00761.

Ciach, G. J., and W. F. Krajewski, 1999: On the estimation of radar rainfall error variance. Adv. Water Resour., 22, 585-595, https://doi.org/10.1016/S0309-1708(98)00043-8.

— E. Eabib, and W. F. Krajewski, 2003: Zero-covariance hypothesis in the error variance separation method of radar rainfall verification. Adv. Water Resour., 26, 573-580, https:// doi.org/10.1016/S0309-1708(02)00163-X.

—, W. F. Krajewski, and G. Villarini, 2007: Product-error-driven uncertainty model for probabilistic quantitative precipitation estimation with NEXRAD data. J. Hydrometeor., 8, 13251347, https://doi.org/10.1175/2007JHM814.1.

Daly, C., R. P. Nelson, and D. L. Phillips, 1994: A statisticaltopographic model for mapping climatological precipitation over mountain terrain. J. Appl. Meteor., 33, 140-158, https:// doi.org/10.1175/1520-0450(1994)033<0140:ASTMFM > 2.0.CO;2.

Diamond, H. J., and Coauthors, 2013: U.S. Climate Reference Network after one decade of operations: Status and assessment. Bull. Amer. Meteor. Soc., 94, 485-498, https://doi.org/ 10.1175/BAMS-D-12-00170.1.

Ferraro, R., B. R. Nelson, T. Smith, and O. P. Prat, 2018: The AMSU-based hydrological bundle climate data record Description and comparison with other data sets. Remote Sens., 10, 1640, https://doi.org/10.3390/rs10101640.

Gebremichael, M., M. M. Bitew, F. A. Hirpa, and G. N. Tesfay, 2014: Accuracy of satellite rainfall estimates in the Blue Nile Basin: Lowland plain versus highland mountain. Water Resour. Res., 50, 8775-8790, https://doi.org/10.1002/2013WR014500.

Habib, E., G. J. Ciach, and W. F. Krajewski, 2004: A method for filtering out raingauge representativeness errors from the verification distributions of radar and raingauge rainfall. Adv. Water Resour., 27, 967-980, https://doi.org/10.1016/ j.advwatres.2004.08.003.

Hibbert, A. R., 1977: Distribution of precipitation on rugged terrain in Central Arizona. Hydrol. Water Resour. Arizona Southwest, 7, 163-173.

Hirpa, F. A., M. Gebremichael, and T. Hopson, 2010: Evaluation of high-resolution satellite precipitation products over very complex terrain in Ethiopia. J. Appl. Meteor. Climatol., 49, 1044-1051, https://doi.org/10.1175/2009JAMC2298.1.

Hsu, K., H. Ashouri, D. Braithwaite, and S. Sorooshian, 2014: Precipitation PERSIANN-CDR. Climate Algorithm Theoretical Basis Doc., revision 2, 30 pp., .https://www1.ncdc.noaa.gov/pub/ data/sds/cdr/CDRs/PERSIANN/AlgorithmDescription_01B-16.

Huffman, G. J., R. F. Adler, M. Morrissey, D. Bolvin, S. Curtis, R. Joyce, B. McGavock, and J. Susskind, 2001: Global precipitation at one-degree daily resolution from multi-satellite observations. J. Hydrometeor., 2, 36-50, https://doi.org/10.1175/ 1525-7541(2001)002<0036:GPAODD > 2.0.CO;2.

- and Coauthors, 2007: The TRMM Multisatellite Precipitation Analysis (TMPA): Quasi-global, multiyear, combined-sensor precipitation estimates at fine scales. J. Hydrometeor., 8, 3855, https://doi.org/10.1175/JHM560.1.

Joyce, R., J. Janowiak, P. Arkin, and P. Xie, 2004: CMORPH: A method that produces global precipitation estimates from passive microwave and infrared data at high spatial and temporal resolution. J. Hydrometeor., 5, 487-503, https://doi.org/ 10.1175/1525-7541(2004)005<0487:CAMTPG > 2.0.CO;2.

Katiraie-Boroujerdy, P.-S., A. A. Asanjan, K.-L. Hsu, and S. Sorooshian, 2017: Intercomparison of PERSIANN-CDR and TRMM-3B42V7 precipitation estimates at monthly and daily time scales. Atmos. Res., 193, 36-49, https://doi.org/10.1016/j.atmosres.2017.04.005.

Kidd, C., and G. Huffman, 2011: Global precipitation measurement. Meteor. Appl., 18, 334-353, https://doi.org/10.1002/met.284.

— V. Levizzani, and S. Laviola, 2010: Quantitative precipitation estimation from Earth observation satellites. Rainfall: State of the science, Geophys. Monogr., Vol. 191, Amer. Geophys. Union, 127-158.

Leeper, R. D., M. A. Palecki, and E. Davis, 2015: Methods to calculate precipitation from weighing-bucket gauges with redundant depth measurements. J. Atmos. Oceanic Technol., 32, 1179-1190, https://doi.org/10.1175/JTECH-D-14-00185.1.

Massari, C., W. Crow, and L. Brocca, 2017: An assessment of the performance of global rainfall estimates without groundbased observations. Hydrol. Earth Syst. Sci., 21, 4347-4361, https:// doi.org/10.5194/hess-21-4347-2017.

Menne, M. J., I. Durre, S. Vose, B. E. Gleason, and T. G. Houston, 2012: An overview of the Global Historical Climatology Network-Daily database. J. Atmos. Oceanic Technol., 29, 897910, https://doi.org/10.1175/JTECH-D-11-00103.1.

Miao, C., H. Ashouri, K.-L. Hsu, S. Sorooshian, and Q. Duan, 2015: Evaluation of the PERSIANN-CDR daily rainfall estimates in capturing the behavior of extreme precipitation events over China. J. Hydrometeor., 16, 1387-1396, https://doi.org/10.1175/ JHM-D-14-0174.1.

Michaelides, S., V. Levizzani, E. Anagnostou, P. Bauer, T. Kasparis, and J. E. Lane, 2009: Precipitation: Measurement, remote sensing, climatology and modeling. Atmos. Res., 94, 512-533, https:// doi.org/10.1016/j.atmosres.2009.08.017.

National Research Council, 2004: Climate Data Records from Environmental Satellites: Interim Report. The National Academies Press, 150 pp., https://doi.org/10.17226/10944.

Nelson, B. R., O. P. Prat, D.-J. Seo, and E. Habib, 2016: Assessment and implications of NCEP Stage IV quantitative precipitation estimates for product intercomparisons. Wea. Forecasting, 31, 371-394, https://doi.org/10.1175/WAF-D-14-00112.1.

Nguyen, P., M. Ombadi, S. Sorooshian, K.-L. Hsu, A. AghaKouchak, D. Braithwaite, H. Ashouri, and A. R. Thorstensen, 2018: The PERSIANN family of global satellite precipitation data: A review and evaluation of products. Hydrol. Earth Syst. Sci., 22, 5801-5816, https://doi.org/10.5194/hess-22-5801-2018.

Nickl, E. C., 2012: Variability in land surface precipitation estimates over 100 plus years with emphasis in mountainous regions. Ph.D. thesis, University of Delaware, $129 \mathrm{pp}$.

Prat, O. P., and B. R. Nelson, 2014: Characteristics of annual, seasonal, and diurnal precipitation in the Southeastern United States derived from long-term remotely sensed data. Atmos. Res., 144, 4-20, https://doi.org/10.1016/j.atmosres.2013.07.022. , and - 2015: Evaluation of precipitation estimates over CONUS derived from satellite, radar, and rain gauge data sets at daily to annual scales (2002-2012). Hydrol. Earth Syst. Sci., 19, 2037-2056, https://doi.org/10.5194/hess-19-2037-2015.

— extreme rainfall. Satellite Precipitation Measurement, V. Levizzani 
et al. Eds., Vol. 2, Springer, 761-790, https://doi.org/10.1007/978-3030-35798-6_16.

, R. D. Leeper, J. E. Bell, B. R. Nelson, J. Adams, and S. Ansari, 2018: Toward earlier drought detection using remotely sensed precipitation data from the Reference Environmental Data Record (REDR) CMORPH. Geophysical Research Abstracts, Vol. 20, Abstract EGU2018-11468-1, https:// meetingorganizer.copernicus.org/EGU2018/EGU2018-11468-1.pdf.

—_, A. M. Courtright, R. D. Leeper, B. R. Nelson, R. Bilotta, J. Adams, and S. Ansari, 2020: Operational near-real time drought monitoring using global satellite precipitation estimates. 2020 EGU General Assembly, Online, EGU, EGU2020-14871, https://doi.org/10.5194/egusphere-egu202014871.

Sadeghi, M., A. A. Asanjan, M. Faridzad, V. A. Gorooh, P. Nguyen, K. L. Hsu, S. Sorooshian, and D. Braithwaite, 2019: Evaluation of PERSIANN-CDR constructed using GPCP V2.2 and V2.3 and a comparison with TRMM 3B42 V7 and CPC unified gauge-based analysis in global scale. Remote Sens., 11, 2755, https://doi.org/ 10.3390/rs11232755.

Schermerhorn, V. P., 1967: Relations between topography and annual precipitation in western Oregon and Washington. Water Resour. Res., 3, 707-711, https://doi.org/10.1029/WR003i003p00707.

Smith, R. B., 1979: The influence of mountains on the atmosphere. Advances in Geophysics, Vol. 21, Academic Press, 87-230, https://doi.org/10.1016/S0065-2687(08)60262-9.

Sorooshian, S., K. Hsu, X. Gao, H. Gupta, B. Imam, and D. Braithwaite, 2000: Evolution of the PERSIANN system satellite-based estimates of tropical rainfall. Bull. Amer. Meteor. Soc., 81, 2035-2046, https://doi.org/10.1175/1520-0477(2000) 081<2035:EOPSSE >2.3.CO;2.

Spreen, W. C., 1947: A determination of the effect of topography upon precipitation. Trans. Amer. Geophys. Union, 28, 285290, https://doi.org/10.1029/TR028i002p00285.

Stampoulis, D., and E. N. Anagostou, 2012: Evaluation of global satellite rainfall products over continental Europe. J. Hydrometeor., 13, 588-603, https://doi.org/10.1175/JHM-D11-086.1.
Sun, Q., C. Miao, Q. Duan, H. Ashouri, S. Sorooshian, and K.-L. Hsu, 2018: A review of global precipitation datasets: data sources, estimation, and intercomparisons. Rev. Geophys., 56, 79-107, https://doi.org/10.1002/2017RG000574.

Tan, M. L., and H. Santo, 2018: Comparison of GPM IMERG, TMPA 3B42 and PERSIANN-CDR satellite precipitation products over Malaysia. Atmos. Res., 202, 63-76, https:// doi.org/10.1016/j.atmosres.2017.11.006.

Tapiador, F. J., and Coauthors, 2012: Global precipitation measurement: Methods, datasets and applications. Atmos. Res., 104-105, 70-97, https://doi.org/10.1016/j.atmosres.2011.10.021.

Tian, Y., and C. D. Peters-Lidard, 2010: A global map of uncertainties in satellite-based precipitation measurements. Geophys. Res. Lett., 37, L24407, https://doi.org/10.1029/2010GL046008.

— based precipitation estimates. J. Geophys. Res., 144, D24101, https://doi.org/10.1029/2009JD011949.

USGS, 1996: Global 30 Arc Second Elevation Data (GTOPO 30). U.S. Geological Survey, accessed 17 August 2021, https:// doi.org/10.5066/F7DF6PQS.

Xie, P., J. E. Janowiak, P A. Arkin, R. Adler, A. Gruber, R. Ferraro, G. J. Huffman, and S. Curtis, 2003: GPCP pentad precipitation analyses: An experimental dataset based on gauge observations and satellite estimates. J. Climate, 16, 2197-2214, https://doi.org/10.1175/2769.1.

—, M. Chen, and W. Shi, 2010: CPC Unified gauge-based analysis of global daily precipitation. 24th Conf. on Hydrology, Atlanta, GA, Amer. Meteor. Soc., 2.3A, https://ams.confex.com/ams/ 90annual/webprogram/Paper163676.html.

_- R. Joyce, S. Wu, S.-H. Yoo, Y. Yarosh, F. Sun, and R. Lin, 2017: Reprocessed, bias-corrected CMORPH global highresolution precipitation estimates from 1998. J. Hydrometeor., 18, 1617-1641, https://doi.org/10.1175/JHM-D-16-0168.1.

$\longrightarrow, \ldots$, and,- 2018 : Bias-corrected CMORPH high-resolution global precipitation estimates. Climate Algorithm Theoretical Basis Doc, 35 pp., https://www1.ncdc.noaa.gov/pub/data/sds/ cdr/CDRs/Precipitation-CMORPH/AlgorithmDescription_ 01B-23.pdf. 